\title{
Low melting point, high thermal stable branched benzoxazines resin derived from mixed-substituted phosphazene core
}

\author{
H-X.Ma ${ }^{1,2}, J-J . Q i u^{1}, C-M$. Liu $^{1 *}$ \\ ${ }^{1}$ College of Chemistry and Chemical Engineering, Key Laboratory for Large-formal Battery Materials and System, \\ Ministry of Education, Huazhong University of Science and Technology, 430074 Wuhan, China \\ ${ }^{2}$ Department of Chemical and Environmental Engineering, Wuhan Institute of Bioengineering, 430415 Wuhan, China
}

Received 6 June 2019; accepted in revised form 19 August 2019

\begin{abstract}
Six fluorine-containing, mix-substituted phosphazene-based branched benzoxazine monomers with a low melting point were successfully prepared and their chemical structures were verified by ${ }^{1} \mathrm{H},{ }^{13} \mathrm{C},{ }^{31} \mathrm{P}$ and ${ }^{19} \mathrm{~F}$ nuclear magnetic resonance (NMR). These branched benzoxazine resins underwent thermal ring-opening polymerization to form cured polymers with high thermal stability both in $\mathrm{N}_{2}$ atmosphere and in air. The co-substituents, both $m-\mathrm{CF}_{3} \mathrm{PhOH}$ and $p-\mathrm{CF}_{3} \mathrm{PhOH}$, imposed significant effects on processing, thermal, and surface properties of corresponding polybenzoxazines. Non-isothermal differential scanning calorimetry (DSC) under diverse heating rates was adopted to investigate the curing kinetics and determine the activation energy of polymerization. DSC results indicate that the $m-\mathrm{CF}_{3} \mathrm{PhO}-/ p-\mathrm{CF}_{3} \mathrm{PhO}-$ groups have the potential to lower ring-opening polymerization temperature. Glass transition temperatures $\left(T_{\mathrm{g}} \mathrm{s}\right)$ of polybenzoxazines derived from $p-\mathrm{CF}_{3} \mathrm{PhOH}$ are higher than that of polymers derived from $m-\mathrm{CF}_{3} \mathrm{PhOH}$ due to different steric hindrance and crosslinking density. More interesting, all polybenzoxazines show relatively high dielectric constant but exhibit low dielectric loss at ambient temperature.
\end{abstract}

Keywords: thermosetting resins, branched benzoxazine monomer, phosphazene-core, low melting point, high thermal stability

\section{Introduction}

1,3-Benzoxazine, a monomer of newly developed thermosetting resins called polybenzoxazines (PBZ), can be synthesized conveniently from primary amine, formaldehyde, and phenol by one-pot Mannich condensation $[1,2]$. Due to the wide range of selectivity of raw materials, it provides benzoxazines with molecular design flexibility and can meet the practical requirement by designing different monomer structures [3-20]. For example, the tetra-functional fluorene-based benzoxazine resin (t-BF-a-c) was synthesized, which exhibits an exothermal peak at $276^{\circ} \mathrm{C}$, and displays good processability and wide process window $\left(60^{\circ} \mathrm{C}\right)$ due to the incorporation of cardanol
[21]. The main merits of PBZs include excellent mechanical and thermal properties, high char-formation ability [2, 22], low dielectric loss [23], low water absorption [24-28]. The furan-containing tetrafunctional fluorene-based benzoxazine monomer ( $\mathrm{t}-\mathrm{BF}-\mathrm{f}$ ) was prepared, which exhibits extremely higher glass transition temperature $\left(440^{\circ} \mathrm{C}\right)$ and better thermal stability than difunctional furan-containing fluorenebased polybenzoxazine, ascribed to its higher crosslinking density of poly(t-BF-f) [29]. Besides, most PBZs possess excellent dimensional stability due to their high crosslinking density, and this character makes it a suitable polymer matrix resin for polymer composites. Many benzoxazine-based composites

\footnotetext{
*Corresponding author, e-mail: liukui@mail.hust.edu.cn (C) BME-PT
} 
have been studied [30-34]. However, most benzoxazine resins appear as high melting point powders, and organic solvents [35] are always needed when preparing benzoxazine composites. Obviously, organic solvent will bring about environmental issues and make the process complicated. Water was also used as a processing aid for benzoxazine composite preparation, but before curing, water still need to be removed from the system [33]. Another approach to lower the melting point of benzoxazine resin is introducing flexible chain [36-38] or functional group [39] into benzoxazine structure, but the improvement of processability is obtained at the sacrifice of the mechanical and thermal properties to some extent. Hence design and preparation of benzoxazine monomer with a low melting point but without decreasing its properties is a current challenge.

It has been proved that the incorporation of fluorinated substituents into polybenzoxazines [40, 41] can improve the thermal stability [42] and lower its dielectric constant $[43,44]$ due to the small dipole moment and low polarizability of the $\mathrm{C}-\mathrm{F}$ bond [45]. Thus the fluorine content in main-chain polybenzoxazines leads to better hydrophobic property [46, 47], which seemed very suitable for oil-water separation driven by gravity [48-50]. Undoubtedly, fluorinated benzoxazines have attracted many attentions and gradually become a research focus [51-53].

Recently, our group focused on preparing organicinorganic hybrid polybenzoxazines based on cyclotriphosphazene core, and this kind of resins exhibited excellent thermal stability and easy preparation [54 57]. Though these monomers have higher molecular weights $(>1490 \mathrm{~g} / \mathrm{mol})$ compared that with traditithe onal bisphenol-A based benzoxazine monomer, but some of them showed relatively low melting point $\left(32-84^{\circ} \mathrm{C}\right)$ [57] and have the potential to be used as a matrix resin for composite preparation. With the aid of high molecular design flexibility of phosphazene-based benzoxazine, we try to introduce fluorine-containing high polar group, such as $m-\mathrm{CF}_{3} \mathrm{PhOH} / p-\mathrm{CF}_{3} \mathrm{PhOH}$, into cyclotriphosphazene core to prepare mixed-substituted phosphazenebased benzoxazine derivatives to obtain benzoxazine monomers with a low melting point or even liquidlike monomers. In this research, six benzoxazine monomers with branched structure (Figure 1) and different functionality were obtained by a nucleophilic reaction. These benzoxazine monomers appear as liquid or low melting point solid suitable for composites preparation. More attractively, after polymerization, all fluorine-containing polybenzoxazines show high heat resistance both in $\mathrm{N}_{2}$ and in air atmosphere, and the highest glass transition temperature is as high as $218^{\circ} \mathrm{C}$.

\section{Experimental}

\subsection{Materials}

Salicylaldehyde $(\geq 98 \%)$, sodium borohydride (96\% $\geq$ ), 4-aminophenol ( $\geq 98 \%$ ), paraformaldehyde $(\geq 95 \%)$, potassium carbonate and sodium hydroxide were all gained from Guoyao Chemical Reagent Co., Ltd., Shanghai, China. $m-\mathrm{CF}_{3} \mathrm{PhOH}[3$-(Trifluoromethyl)phenol] $\left(\geq 98 \%\right.$ ), $p-\mathrm{CF}_{3} \mathrm{PhOH}[4$-(Trifluoromethyl)phenol] $(\geq 98 \%)$, were supplied by Alfa Aesar Reagent Co, Ltd., Missouri, USA. Hexachlorocyclotriphosphazene $\left[\mathrm{N}_{3} \mathrm{P}_{3} \mathrm{Cl}_{6}\right.$, trimer $]$ was recrystallized before utilization. All other reagents were used directly after received.

\subsection{Measurements}

Chemical structure of all compounds was identified by Proton $\left({ }^{1} \mathrm{H}\right)$, Carbon $\left({ }^{13} \mathrm{C}\right)$, Phosphorus $\left({ }^{31} \mathrm{P}\right)$ and Fluorine $\left({ }^{19} \mathrm{~F}\right)$ NMR spectroscopy which recorded on Bruker AV400 NMR spectrometer (Bruker, Co., Ltd., Switzerland) and taking deuterated solvent DMSO- $d_{6}$ as the solvent. FTIR (Fourier transform infrared) spectra were taken on Bruker Vertex 70 FTIR spectrometer (BrukerDaltonics, Inc., USA) with a resolution of $4 \mathrm{~cm}^{-1}$ between $4000-400 \mathrm{~cm}^{-1}$. The rheological behavior was studied with a rotational rheometer (MCR302 SN81054732, Beijing Hongchangxin Technology co., LTD, Beijing, China) at $100^{\circ} \mathrm{C}$. Thermal transitions were monitored with DSC instrument NETZSCH Model 404F3 from NETZSCH, Inc. (Bavaria, Germany) within the temperature range of $30-300^{\circ} \mathrm{C}$ at a scanning rate of $10^{\circ} \mathrm{C} / \mathrm{min}$, nitrogen flow rate of $50 \mathrm{ml} / \mathrm{min}$. Thermal stability of polybenzoxazines was investigated through thermogravimetric analysis on NETZSCH High-Resolution STA 409PC thermogravimetric analyzer (TGA) (NETZSCH instrument manufacturing co., Ltd., Selb, Germany) under nitrogen purging rate of $60 \mathrm{ml} / \mathrm{min}$, at a heating rate of $10^{\circ} \mathrm{C} / \mathrm{min}$ and scanning temperature range between 30 to $900^{\circ} \mathrm{C}$. The bulk properties of polybenzoxazines were measured on a dynamic mechanical thermal analysis apparatus (Diamond DMA, PerkinElmer Inc., Waltham, USA) in 3-point bending mode with specimens dimension of $50 \times 10 \times 1.0 \mathrm{~mm}$. The thermal transition 
of samples was investigated in the temperature scope of $30-300^{\circ} \mathrm{C}$, with a frequency of $1 \mathrm{~Hz}$ and heating rate of $4^{\circ} \mathrm{C} / \mathrm{min}$. A contact angle goniometer, POWEREACH JC2000C1 (Shanghai Zhongchen digital technology equipment co., Ltd., Shanghai, China), was employed to measure the advancing contact angle $\left(\theta_{\mathrm{a}}\right)$ and the receding contact angle $\left(\theta_{\mathrm{r}}\right)$ of film samples at $25^{\circ} \mathrm{C}$. During $\theta_{\mathrm{a}}$ measurement, drop volume increased from 3 to $7 \mu \mathrm{l}$, when measuring $\theta_{\mathrm{r}}$, drop volume decreased to $3 \mu \mathrm{l}$. In the course of measuring both $\theta_{\mathrm{a}}$ and $\theta_{\mathrm{r}}$, the needle always maintained within the droplet. For each sample, a minimum of three different readings was recorded. $n$-Hexadecane and deionized water were used as a standard. Dielectric properties of film samples were recorded on Agilent 4294A Precision Impedance Analyzer (Agilent Technologies, Inc., Palo Alto, USA) at ambient temperature in the frequency range of $100 \mathrm{~Hz}-1 \mathrm{MHz}$. Before each measurement, the samples were coated with InGa electrodes. The size of the samples was about $20 \times 10 \times 2 \mathrm{~mm}$. Monomers were compressed into tablets, $12 \mathrm{~mm}$ in diameter, the thickness of $2 \mathrm{~mm}$.

\subsection{Curing kinetic analysis}

Non-isothermal DSC (differential scanning calorimetry) method was used to study the curing behavior. The activation energy of polymerization was calculated separately by Kissinger, Ozawa and Flynn-Wall-Ozawa's method [58] based on the DSC data taking at a heating rate of $2,5,10,15$, and $20^{\circ} \mathrm{C} \cdot \mathrm{min}^{-1}$.

\subsection{Monomer synthesis: Preparation of monomer $4 \mathrm{~m}, 3 \mathrm{~m}, \mathbf{2 m}, \mathbf{4 p}, 3 \mathrm{p}$ and $2 \mathrm{p}$}

Six monomers were prepared according to the reported procedure [57]. The reaction details and chemical structure of six branched monomers with phosphazene core were presented in Figure 1. The monomers were named as $N m$ and $N p .(N=4,3,2$, which express the number of co-substituent, $\mathrm{m} / \mathrm{p}$ represents $m / p-\mathrm{CF}_{3} \mathrm{PhOH}$ ).

General procedures for preparing the monomers: Preparation of $4 m\left[\mathrm{~N}_{3} \mathrm{P}_{3}(\mathrm{O}-\mathrm{BOZ})_{2}\left(\mathrm{OC}_{6} \mathrm{H}_{5}-m-\mathrm{CF}_{3}\right)_{4}\right]$ : $\left[\mathrm{N}_{3} \mathrm{P}_{3} \mathrm{Cl}_{6}\right](4.00 \mathrm{~g}, 11.5 \mathrm{mmol}, 1 \mathrm{eq})$, activated $\mathrm{K}_{2} \mathrm{CO}_{3}(12.72 \mathrm{~g}, 92 \mathrm{mmol}, 8 \mathrm{eq})$ and acetonitrile $(150 \mathrm{ml})$ were charged into a three-necked $500 \mathrm{ml}$ round-bottom flask with vigorous agitation under ice-water bath at $0^{\circ} \mathrm{C}$, then a calculated amount of
HO-BOZ (5.26 g, $23 \mathrm{mmol}, 2 \mathrm{eq})$ dissolved in $100 \mathrm{ml}$ acetonitrile was added dropwise into the suspension. Then, the mixture was agitated under an ambient condition in an argon atmosphere for nearly $5 \mathrm{~h}$, and the process was monitored by TLC (thinlayer chromatography). After the $\mathrm{HO}-\mathrm{BOZ}$ was consumed completely, the excess amount of $m-\mathrm{CF}_{3} \mathrm{PhOH}$ (or $\left.p-\mathrm{CF}_{3} \mathrm{PhOH}\right)(5.67 \mathrm{~g}, 60 \mathrm{mmol}$,

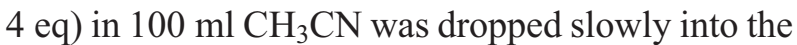
reaction mixture under vigorous agitation, then let the temperature rose to $85^{\circ} \mathrm{C}$ and kept at this temperature for 10 hours. Then cooled the reaction mixture to ambient temperature, solid salts (remaining $\mathrm{K}_{2} \mathrm{CO}_{3}$ and produced $\mathrm{KCl}$ ) were filtered out and the filtrate was condensed under vacuum at $40^{\circ} \mathrm{C}$ by rotary evaporation. The residue was dissolved in $\mathrm{CH}_{2} \mathrm{Cl}_{2}(120 \mathrm{ml})$, extracted three times with $5 \%$ sodium hydroxide and finally washed with pure water until the water phase was neutral. The $\mathrm{CH}_{2} \mathrm{Cl}_{2}$ solution was dried by anhydrous $\mathrm{MgSO}_{4}$ overnight. Then the solvent was removed by rotary evaporation at under vacuum to give pale yellow viscous liquid (target product $\mathrm{N}_{3} \mathrm{P}_{3}(\mathrm{O}-\mathrm{BOZ})_{2}\left(\mathrm{OC}_{6} \mathrm{H}_{5}-m-\mathrm{CF}_{3}\right)_{4}$ $13.03 \mathrm{~g}$, yield $92.0 \%$ ). The other monomers were prepared with similar procedure. The chemical structures of six benzoxazines are shown in Figure 1.

$4 m$ : pale yellow viscous liquid, yield $92 \%,{ }^{1} \mathrm{H}$ NMR (ppm, DMSO- $\left.d_{6}, \mathrm{TMS}\right): 4.64\left(\mathrm{~s}, 4 \mathrm{H}, \mathrm{CH}_{2} \mathrm{~N}\right), 5.43$ (s, $\left.4 \mathrm{H}, \mathrm{OCH}_{2} \mathrm{~N}\right), 6.75-7.53(\mathrm{~m}, 32 \mathrm{H}, \mathrm{CH}) .{ }^{31} \mathrm{P} \mathrm{NMR}(\delta$, DMSO- $\left.d_{6}\right): 8.77-9.03 .{ }^{19} \mathrm{~F}$ NMR $\left(\delta\right.$, DMSO- $\left.d_{6}\right)$ : $-61.64-61.38\left(\mathrm{CF}_{3}\right)$.

3m: pale yellow viscous liquid, 91\% yield, ${ }^{1} \mathrm{H}$ NMR (ppm, DMSO- $\left.d_{6}, \mathrm{TMS}\right): 4.62\left(\mathrm{~s}, 6 \mathrm{H}, \mathrm{CH}_{2} \mathrm{~N}\right), 5.41$ $\left(\mathrm{s}, 6 \mathrm{H}, \mathrm{OCH}_{2} \mathrm{~N}\right), 6.63-7.54(\mathrm{~m}, 36 \mathrm{H}, \mathrm{CH}) .{ }^{31} \mathrm{P}$ NMR $\left(\delta\right.$, DMSO- $\left.d_{6}\right): 8.97-9.13,{ }^{19} \mathrm{~F}$ NMR $\left(\delta\right.$, DMSO- $\left.d_{6}\right)$ : $-61.59-61.29\left(\mathrm{CF}_{3}\right)$.

$2 m$ : light yellow powder, $87 \%$ yield, mp. $35.7^{\circ} \mathrm{C}$. ${ }^{1} \mathrm{H}$ NMR (D ppm, MSO $\left.d_{6}, \mathrm{TMS}\right): 4.60(\mathrm{~s}, 8 \mathrm{H}$, $\left.\mathrm{CH}_{2} \mathrm{~N}\right), 5.39\left(\mathrm{~s}, 8 \mathrm{H}, \mathrm{OCH}_{2} \mathrm{~N}\right), 6.70-7.45(\mathrm{~m}, 40 \mathrm{H}$, $\mathrm{CH}) .{ }^{31} \mathrm{P}$ NMR $\left(\delta, \mathrm{DMSO} d_{6}\right): 9.45-9.70 .{ }^{19} \mathrm{~F}$ NMR $\left(\delta\right.$, DMSO- $\left.d_{6}\right):-61.39--61.24\left(\mathrm{CF}_{3}\right)$.

4p: light yellow powder, $91.0 \%$ yield, mp. $40.2{ }^{\circ} \mathrm{C}$. ${ }^{1} \mathrm{H}$ NMR (D ppm, MSO- $d_{6}$, TMS): 4.61 (s, $4 \mathrm{H}$, $\left.\mathrm{CH}_{2} \mathrm{~N}\right), 5.40\left(\mathrm{~s}, 4 \mathrm{H}, \mathrm{OCH}_{2} \mathrm{~N}\right), 6.71-7.51(\mathrm{~m}, 32 \mathrm{H}$, $\mathrm{CH}) .{ }^{31} \mathrm{P}$ NMR $\left(\delta\right.$, DMSO- $\left.d_{6}\right): 8.99-9.22 .{ }^{19} \mathrm{~F}$ NMR $\left(\delta\right.$, DMSO- $\left.d_{6}\right)$ : $-60.71--60.43\left(\mathrm{CF}_{3}\right)$.

3p: light yellow powder, $89.0 \%$ yield, mp. $46.3^{\circ} \mathrm{C}$. ${ }^{1} \mathrm{H}$ NMR (ppm, DMSO- $\left.d_{6}, \mathrm{TMS}\right): 4.62(\mathrm{~s}, 6 \mathrm{H}$, $\left.\mathrm{CH}_{2} \mathrm{~N}\right), 5.41\left(\mathrm{~s}, 6 \mathrm{H}, \mathrm{OCH}_{2} \mathrm{~N}\right), 6.72-7.51(\mathrm{~m}, 36 \mathrm{H}$, 


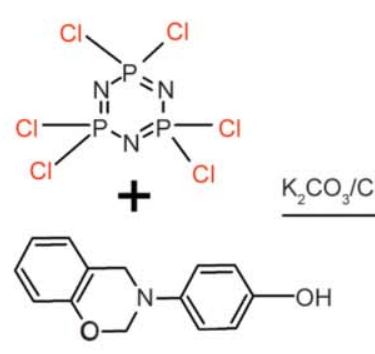

(HO-BOZ)

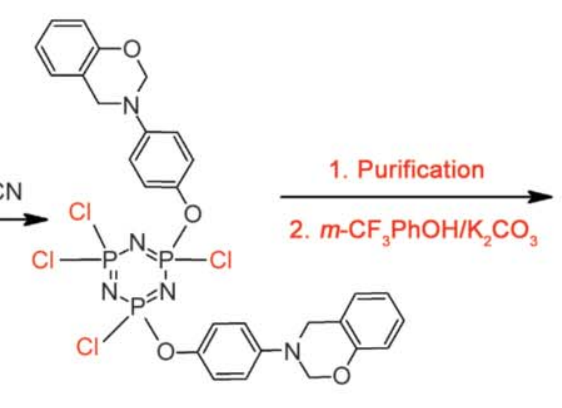

$\mathrm{N}_{3} \mathrm{P}_{3}(\mathrm{OBOZ})_{n} \mathrm{Cl}_{6-n}$ ( $n=0,1,2,3,4,5,6$, possible)
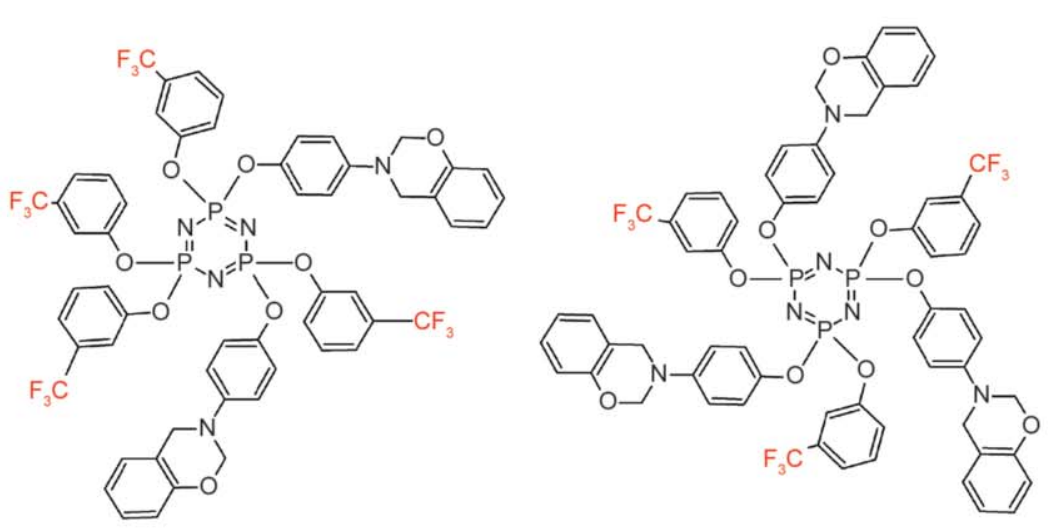

$1-4 m$

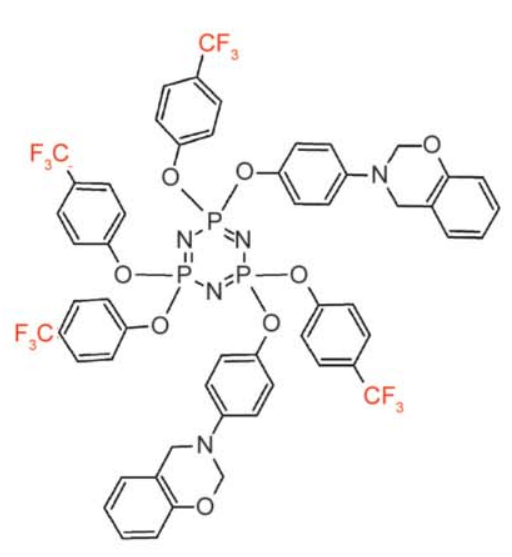

IV $-4 p$

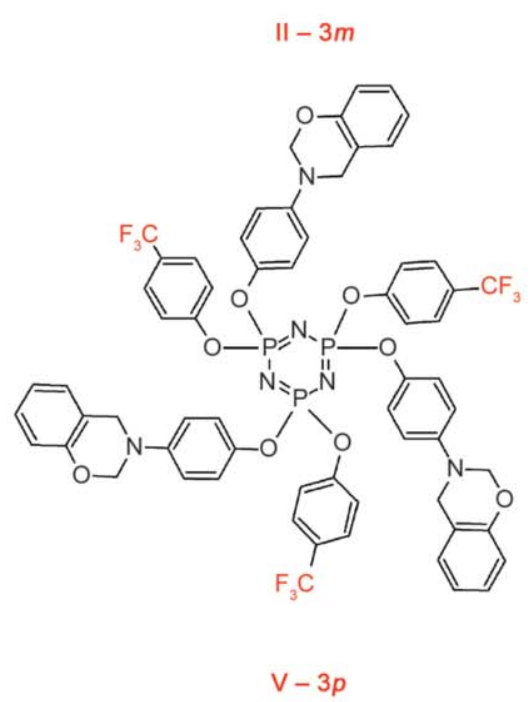

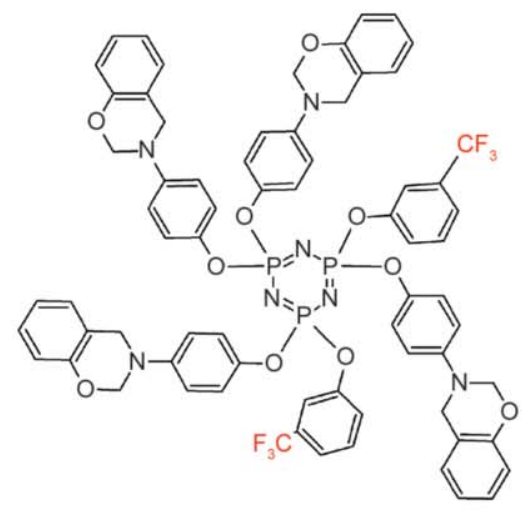<smiles>FC(F)(F)c1cccc(OP2(Oc3ccc(N4COc5ccccc5C4)cc3)=NP(Oc3cccc(C(F)(F)F)c3)(Oc3cccc(C(F)(F)F)c3)=NP(Oc3cccc(N4COc5ccccc5C4)c3)(Oc3cccc(C(F)(F)F)c3)=N2)c1</smiles>

$\mathrm{N}_{3} \mathrm{P}_{3}(\mathrm{OBOZ})_{2}\left(\mathrm{OPh}-\mathrm{mCF}_{3}\right)_{4}$

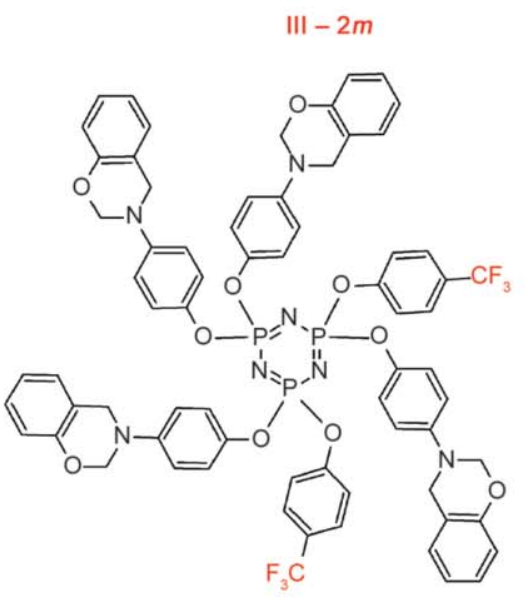

$\mathrm{VI}-2 p$

Figure 1. Synthesis of cyclotriphosphazene-based mixed substituted benzoxazines.

$\mathrm{CH}) .{ }^{31} \mathrm{P}$ NMR $\left(\delta\right.$, DMSO- $\left.d_{6}\right): 9.22-9.31,{ }^{19} \mathrm{~F}$ NMR $\left(\delta\right.$, DMSO- $\left.d_{6}\right)$ : $-60.96--60.46\left(\mathrm{CF}_{3}\right)$.

2p: light yellow powder, $87 \%$ yield, mp. $56.2^{\circ} \mathrm{C}$. ${ }^{1} \mathrm{H}$ NMR (ppm, DMSO- $\left.d_{6}, \mathrm{TMS}\right): 4.60$ (s, 8H, $\left.\mathrm{CH}_{2} \mathrm{~N}\right), 5.40\left(\mathrm{~s}, 8 \mathrm{H}, \mathrm{OCH}_{2} \mathrm{~N}\right), 6.95-7.65(\mathrm{~m}, 40 \mathrm{H}$, $\mathrm{CH}) .{ }^{31} \mathrm{P}$ NMR $\left(\delta\right.$, DMSO- $\left.d_{6}\right): 9.22-9.59 .{ }^{19} \mathrm{~F}$ NMR $\left(\delta\right.$, DMSO- $\left.d_{6}\right)$ : $-60.71--60.43\left(\mathrm{CF}_{3}\right)$.

\subsection{Curing reaction of benzoxazine monomers}

The six monomers were added to six aluminum foil molds and heated up to $120^{\circ} \mathrm{C}$ under vacuum for $1 \mathrm{~h}$. Later, the samples were cured in an air-circulating temperature-controlled oven as following: $200^{\circ} \mathrm{C} / 2 \mathrm{~h}$, $220^{\circ} \mathrm{C} / 2 \mathrm{~h}, 230^{\circ} \mathrm{C} / 2 \mathrm{~h}, 240^{\circ} \mathrm{C} / 2 \mathrm{~h}$ then post-cured at 
$250{ }^{\circ} \mathrm{C}$ for $1 \mathrm{~h}$. When finishing curing, the temperature was allowed to bring back gradually to room temperature to prevent samples cracking. Then six polymers ( $\mathrm{P} 4 m, \mathrm{P} 3 m, \mathrm{P} 2 m, \mathrm{P} 4 p, \mathrm{P} 3 p$ and $\mathrm{P} 2 p$ ) were obtained.

\section{Results and discussion}

\subsection{Chemical structure characterization of the six benzoxazines}

The proposed chemical structures of six monomers were collected in Figure 1 and were thoroughly analyzed by NMR technology. The ${ }^{1} \mathrm{H}$ NMR, ${ }^{13} \mathrm{C}$ NMR, ${ }^{31} \mathrm{P}$ NMR and ${ }^{19} \mathrm{~F}$ NMR spectra (DMSO as solvent) of monomer $4 m$ are shown in Figure 2 and the corresponding data of all six monomers are collected in Table 1. Signals (Figure 2a) at $4.60-4.64 \mathrm{ppm}$ $\left(\mathrm{Ar}-\mathrm{CH}_{2}-\mathrm{N}\right)$ and $5.39-5.43 \mathrm{ppm}\left(\mathrm{O}-\mathrm{CH}_{2}-\mathrm{N}\right)$ for benzoxazine structure [59] are observed in all monomers. The multiple peaks at $6.63-7.67 \mathrm{ppm}$ are ascribed to the aromatic protons. The theoretical ratio of the hydrogen atom of $\mathrm{Ar}-\mathrm{CH}_{2}-\mathrm{N}, \mathrm{O}-\mathrm{CH}_{2}-\mathrm{N}$ and all aromatic hydrogen in monomer $4 m$ is $4: 4: 32$ based on its chemical structure, and the experimental ratio according to the integrated peak area of ${ }^{1} \mathrm{H}$ NMR signals is 4.00:3.99:32.81, which proves that there are two benzoxazine units and four $m-\mathrm{CF}_{3} \mathrm{PhO}-$ on cyclotriphosphazene ring in $4 m$. In ${ }^{13} \mathrm{C}$ NMR spectrum of $4 m$ (Figure $2 b$ ), the characteristic carbon resonances of the oxazine ring appear at 49.48 $\left(\mathrm{Ar}-\underline{\mathrm{C}} \mathrm{H}_{2}-\mathrm{N}\right)$ and $79.16 \mathrm{ppm}$ (and $\left.-\mathrm{O}-\underline{\mathrm{CH}}_{2}-\mathrm{N}\right)$, respectively.

Because the six monomers were mix-substituted by $\mathrm{HO}-\mathrm{BOZ}$ and $m-\mathrm{CF}_{3} \mathrm{PhOH} / p-\mathrm{CF}_{3} \mathrm{PhOH}$, the chemical environment of phosphorus atoms in the same monomer is different for its asymmetric nature, so the ${ }^{31} \mathrm{P}$ NMR signals of $4 m$ appeared as multiple peaks around $9.0 \mathrm{ppm}$ (Figure 2c). For there are no other peaks were found, we can conclude that the substitution reaction of cyclotriphosphazene was complete. Besides, the ${ }^{19} \mathrm{~F}$ NMR spectrum of $4 m$ (Figure $2 \mathrm{~d}$ ) shows the characteristic resonance of fluorine atoms of $-\mathrm{CF}_{3}$ at -60 to $-62 \mathrm{ppm}$, which indicates that the $m-\mathrm{CF}_{3} \mathrm{PhOH}$ (or $p-\mathrm{CF}_{3} \mathrm{PhOH}$ ) has been successfully introduced into phosphazene ring. The NMR data of the other five monomers were collected in Table 1 .

\subsection{Curing reaction of six monomers scanned by DSC}

From Table 2, we can find out that all six mixed-substituted monomers show low melting point $\left(<60^{\circ} \mathrm{C}\right)$, and more surprisingly, the monomer $4 m$ and $3 m$ are pale yellow viscous liquids at room temperature, even if the theoretical molecular weight of six monomers are as high as $1231.8 \mathrm{~g} / \mathrm{mol}(4 \mathrm{~m}), 1297.0 \mathrm{~g} / \mathrm{mol}$
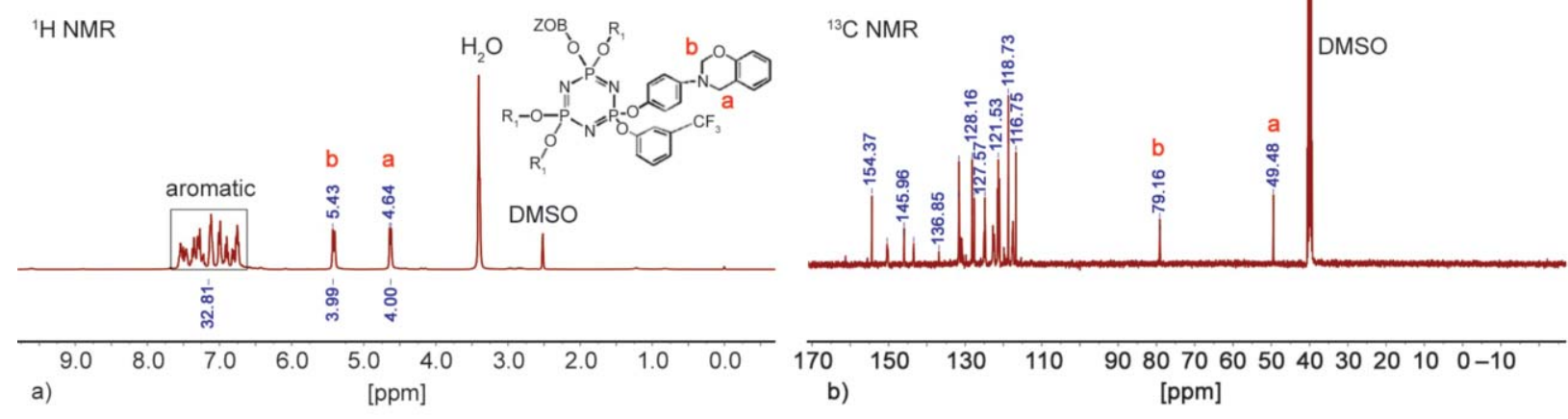

${ }^{31} \mathrm{P}$ NMR

${ }^{19} \mathrm{~F}$ NMR
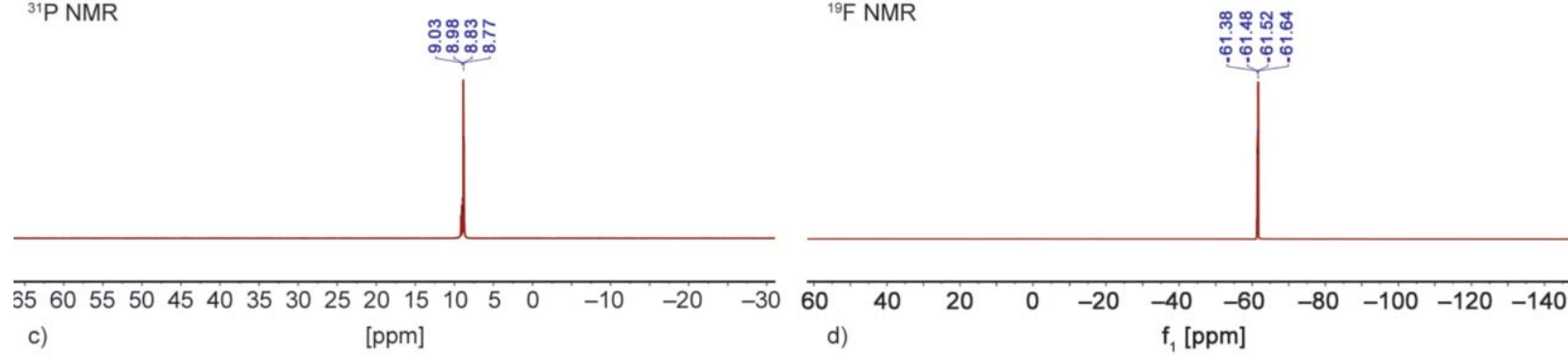

Figure 2. ${ }^{1} \mathrm{H}$ NMR (a), ${ }^{13} \mathrm{C}$ NMR (b), ${ }^{31} \mathrm{P}$ NMR (c) and ${ }^{19} \mathrm{~F}$ NMR (d) spectra of monomer $4 m$. 
Table 1. The data of nuclear magnetic resonance (NMR).

\begin{tabular}{|c|c|c|c|c|c|c|c|c|}
\hline \multicolumn{6}{|c|}{ Monomer } & \multicolumn{3}{|c|}{$\begin{array}{l}\text { NMR } \\
\text { [ppm] }\end{array}$} \\
\hline & \multicolumn{2}{|c|}{$\mathrm{Ar}-\mathrm{CH}_{2}-\mathrm{N}$} & \multicolumn{2}{|c|}{$\mathrm{O}-\mathrm{CH}_{2}-\mathrm{N}$} & \multirow{2}{*}{ Aromatic } & \multirow{2}{*}{$\begin{array}{l}\text { Founded ratio of } \mathrm{H} \text { atom } \\
\text { (a:b:Aromatic) }\end{array}$} & \multirow{2}{*}{${ }^{31} \mathbf{P}$} & \multirow{2}{*}{${ }^{19} \mathrm{~F}$} \\
\hline & & ${ }^{13} \mathrm{C}$ & & ${ }^{13} \mathrm{C}$ & & & & \\
\hline $4 m$ & 4.64 & 49.48 & 5.43 & 79.16 & $6.75-7.53$ & 4.00:3.99:32.81 & $8.77-9.03$ & $-61.64--61.38$ \\
\hline $3 m$ & 4.62 & 49.48 & 5.41 & 79.19 & $6.63-7.54$ & $6.00: 6.10: 36.84$ & $8.97-9.13$ & $-61.59--61.29$ \\
\hline $2 m$ & 4.60 & 49.50 & 5.39 & 79.29 & $6.70-7.45$ & $8.00: 7.92: 40.75$ & $9.45-9.70$ & $-61.39--61.24$ \\
\hline $4 p$ & 4.61 & 49.45 & 5.40 & 79.28 & $6.71-7.67$ & 4.00:3.99:31.90 & $8.99-9.22$ & $-60.71--60.45$ \\
\hline $3 p$ & 4.62 & 49.44 & 5.41 & 79.21 & $6.72-7.62$ & $6.00: 6.01: 36.71$ & $9.22-9.31$ & $-60.96--60.46$ \\
\hline $2 p$ & 4.61 & 49.46 & 5.40 & 79.30 & $6.95-7.60$ & $8.00: 8.08: 40.31$ & $9.22-9.59$ & $-60.71--60.43$ \\
\hline
\end{tabular}

$(3 m), \quad 1362.1 \mathrm{~g} / \mathrm{mol} \quad(2 m), \quad 1231.8 \mathrm{~g} / \mathrm{mol} \quad(4 p)$, $1297.0 \mathrm{~g} / \mathrm{mol}(3 p), 1362.1 \mathrm{~g} / \mathrm{mol}(2 p)$, respectively. $m-\mathrm{CF}_{3} \mathrm{PhOH}$ owers the melting point more effectively than $p-\mathrm{CF}_{3} \mathrm{PhOH}$ because of its asymmetric structure. Furtherly, we measured their viscosity at a shear rate of $60 \mathrm{~s}^{-1}$ at $100^{\circ} \mathrm{C}$ (this temperature is far below the onset polymerization temperature of all monomers), the corresponding viscosities are $0.31(4 m)$, $1.41(3 m), \quad 11.30(2 m), \quad 16.40(4 p), \quad 70.10(3 p)$, $133.80 \mathrm{~Pa} \cdot \mathrm{s}(2 p)$, respectively. Hence, the low melting point and low viscosity provided them with good processing performance and made them suitable for composite preparation.

The polymerization behaviors of six monomers were probed by DSC as depicted in Figure 3, and the corresponding data were collected in Table 2 . Their onset polymerization temperatures $T_{0}$ are as high as $225^{\circ} \mathrm{C}(4 m), 229^{\circ} \mathrm{C}(3 m), 240^{\circ} \mathrm{C}(2 m), 235^{\circ} \mathrm{C}(4 p)$, $235^{\circ} \mathrm{C}(3 p)$ and $248^{\circ} \mathrm{C}(2 p)$, we can figure out that all monomers possess wide processing window $\left(\Delta T>189^{\circ} \mathrm{C}\right.$, please see Table 2 for details $)$ and this character will benefit composites preparation.

From the DSC curves of six monomers (Figure 3), the peak temperature $\left(T_{\max }\right)$ of heat release due to

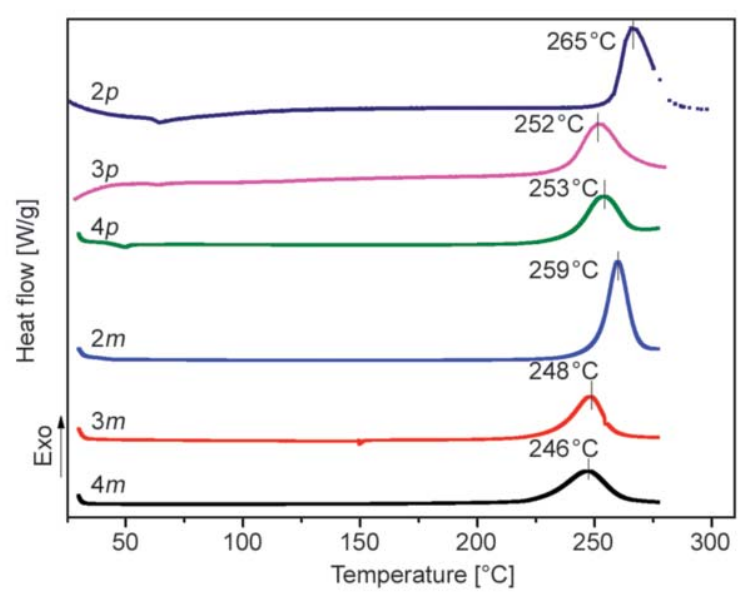

Figure 3. DSC plots of the six benzoxazine monomers under scanning rate of $10^{\circ} \mathrm{C} / \mathrm{min}$. ring-opening polymerization of monomer $4 m$ to $2 p$ centered at $246,248,259,253,252$ and $265^{\circ} \mathrm{C}$, respectively. The monomer $4 m$ (or $4 p$ ) which contains four $m-\mathrm{CF}_{3} \mathrm{PhO}$ - (or $p$ - $\mathrm{CF}_{3} \mathrm{PhO}$-) groups shows lower $T_{\max }$ compared with $2 m$ (or $2 p$ ) which only contains two $m-\mathrm{CF}_{3} \mathrm{PhO}$ - (or $p-\mathrm{CF}_{3} \mathrm{PhO}$-) groups, and the trend is consistent with the onset polymerization temperature. It means that the $m-\mathrm{CF}_{3} \mathrm{PhO}-/ p-\mathrm{CF}_{3} \mathrm{PhO}-$ groups possess the ability to lower the ring-opening polymerization temperature, and the more the cosubstituted groups, the lower the onset polymerization temperature of the corresponding monomer.

For the sake of understanding the details of ring-opening polymerization, non-isothermal DSC methodology was adopted to study the curing behavior of six monomers by different mathematic model. The nonisothermal DSC curves of monomer $3 m$ were presented in Figure 4a. It can be observed that monomer $3 m$ shows only one exothermic peak under different heating rates and the exothermic peak moves to a higher temperature with increasing heating rate. For example, the exothermic peak locates at $218^{\circ} \mathrm{C}$ at a heating rate of $2^{\circ} \mathrm{C} / \mathrm{min}$, it reaches $265^{\circ} \mathrm{C}$ when heating rate increases to $20^{\circ} \mathrm{C} / \mathrm{min}$. From these curves, some curing parameters concerning the nature of the ring-opening polymerization of monomer $3 m$ such as onset polymerization temperature $\left(T_{\mathrm{o}}\right)$, maximum polymerization temperature $\left(T_{\mathrm{p}}\right)$, and the end-up polymerization temperature $\left(T_{\mathrm{m}}\right)$ at different heating rates could be figured out. The relationship between curing parameters (and heating rate $(\varphi)$ is shown in Figure $4 \mathrm{~b}$. By extrapolating the heating rate to zero, the corresponding values of $T_{0}, T_{\mathrm{p}}$ and $T_{\mathrm{m}}$ for monomer $3 m$ are 185,219 and $237^{\circ} \mathrm{C}$, respectively. In the same way, curing parameters of other five monomers at zero heating rate are obtained and listed in Table 2 (marked in green color).

The activation energy $\left(E_{\mathrm{a}}\right)$ of monomer $3 m$ was computed according to Kissinger $\left(E_{\mathrm{K}}\right)$, Ozawa $\left(E_{\mathrm{O}}\right)$ and 
Table 2. The properties of monomers and their corresponding polymerization activation energies.

\begin{tabular}{|c|c|c|c|c|c|c|c|c|c|c|c|c|}
\hline \multicolumn{6}{|c|}{ Monomer } & \multicolumn{3}{|c|}{${ }^{\mathbf{f}}$ Curing parameters } & \multicolumn{4}{|c|}{$\begin{array}{c}E_{\mathrm{a}} \\
{[\mathrm{kJ} / \mathrm{mol}]}\end{array}$} \\
\hline & $\begin{array}{l}{ }^{\mathrm{a}} \boldsymbol{T}_{\mathrm{m}} \\
\left.{ }^{\mathrm{o}}{ }^{\circ} \mathrm{C}\right]\end{array}$ & $\begin{array}{c}{ }^{\text {b} V i s c o s i t y ~} \\
{[\mathrm{~Pa} \cdot \mathrm{s}]}\end{array}$ & $\begin{array}{l}{ }^{\mathbf{c}} \boldsymbol{T}_{\mathbf{0}} \\
{\left[{ }^{\circ} \mathbf{C}\right]}\end{array}$ & $\begin{array}{l}{ }^{\mathrm{d}} \Delta \boldsymbol{T} \\
{\left[{ }^{\circ} \mathbf{C}\right]}\end{array}$ & $\begin{array}{l}{ }^{\mathrm{e}} \boldsymbol{T}_{\max } \\
{\left[{ }^{\circ} \mathbf{C}\right]}\end{array}$ & $\begin{array}{c}T_{0} \\
{\left[{ }^{\circ} \mathrm{C}\right]}\end{array}$ & $\begin{array}{c}T_{\mathrm{p}} \\
{\left[{ }^{\circ} \mathbf{C}\right]}\end{array}$ & $\begin{array}{c}T_{\mathrm{m}} \\
{\left[{ }^{\circ} \mathrm{C}\right]}\end{array}$ & $E_{\mathrm{K}}$ & $E_{\mathrm{O}}$ & $E_{\mathrm{F}-\mathrm{W}-\mathrm{O}}$ & Average \\
\hline $4 m$ & liquid & 0.31 & 225 & $>225$ & 246 & 197 & 217 & 236 & 87.5 & 90.3 & 90.8 & 89.5 \\
\hline $3 m$ & liquid & 1.41 & 229 & $>229$ & 248 & 185 & 219 & 237 & 97.7 & 100.9 & 102.2 & 100.3 \\
\hline $2 m$ & 35 & 11.30 & 240 & 204 & 259 & 216 & 231 & 249 & 98.8 & 102.2 & 100.1 & 100.4 \\
\hline $4 p$ & 40 & 16.40 & 235 & 195 & 253 & 206 & 223 & 241 & 101.7 & 104.0 & 98.8 & 101.8 \\
\hline $3 p$ & 46 & 70.10 & 235 & 189 & 252 & 195 & 222 & 241 & 113.7 & 115.0 & 114.6 & 114.7 \\
\hline $2 p$ & 56 & 133.80 & 248 & 192 & 265 & 228 & 242 & 256 & 120.5 & 122.0 & 119.7 & 120.5 \\
\hline
\end{tabular}

${ }^{\mathrm{a}} T_{\mathrm{m}}$ : Melting point of benzoxazines;

${ }^{b}$ The viscosity at the shear rate of $60 \mathrm{~s}^{-1}$ at $100^{\circ} \mathrm{C}$;

${ }^{\mathrm{c}}$ Onset temperature of the exothermic peak by DSC;

${ }^{\mathrm{d}} \Delta T=T_{\mathrm{o}}-T_{\mathrm{m}} ;$

${ }^{\mathrm{e}}$ Maximum of the polymerization exotherm by DSC;

${ }^{\mathrm{f}}$ Curing temperatures obtained by using $T-\varphi$ extrapolation method.

Flynn-Wall-Ozawa method ( $\left.E_{\mathrm{F}-\mathrm{W}-\mathrm{O}}\right)$, respectively. The corresponding data are presented in Figure $4 \mathrm{c}-$ 4f. The $E_{a}$ value of monomer $3 m$ is $97.7 \mathrm{~kJ} / \mathrm{mol}$ by Kissinger equation, $100.9 \mathrm{~kJ} / \mathrm{mol}$ by Ozawa method, and $102.2 \mathrm{~kJ} / \mathrm{mol}$ by Flynn-Wall-Ozawa method. Three methods give similar results, and the average value of $E_{\mathrm{a}}$ is $100.3 \mathrm{~kJ} / \mathrm{mol}$. The $E_{\mathrm{a}}$ values of the remaining five monomers are obtained by the same procedure, and the results are collected in Table 2. Based on these data, we can deduce that co-substituent, both $m-\mathrm{CF}_{3} \mathrm{PhOH}$ and $p-\mathrm{CF}_{3} \mathrm{PhOH}$ groups, can lower down the activation energy of polymerization to some extent.

\subsection{Thermal properties of the six polybenzoxazines}

Thermal property of thermosetting resins is one of the key factors for their practical applications. The six fluorine-containing polybenzoxazine samples were prepared according to the described conditions in the experimental section. All the cured polybenzoxazines are transparent with a deep-red appearance. The gel fractions (or percentage of cured polymer that is insoluble in chloroform) of the six samples were measured by the standard solvent-extraction method. These values were used to evaluate the conversion rate of monomers. All cured polymers possessed high gel fraction (over 99\%), and these results indicated that nearly all monomers joined together to form crosslinked network due to their high molecular weight nature.

Heat resistance of six cured benzoxazine resins was inquired by TGA (Figure 5). The carbon residue (or char yield) was defined as a solid residue remained at $850{ }^{\circ} \mathrm{C}$ which was estimated using TGA curves in nitrogen $\left(\mathrm{N}_{2}\right)$ atmosphere (Figure 5a) and in an air atmosphere (Figure $5 b$ ). The corresponding data for all polybenzoxazines are summarized in Table 3. It was found that 5 and $10 \%$ weight-loss temperatures of all polybenzoxazines were above $350,365^{\circ} \mathrm{C}$, respectively, not only in $\mathrm{N}_{2}$, but also in air atmosphere. And char yield of all polymers is more than $45 \%$ in $\mathrm{N}_{2}$, and more than $10 \%$ in air. Such results are really inspiring because it means that all six polymers show outstanding thermal stability both in nitrogen and in air atmosphere compared with that of previous reports $[60,61]$. It is thought that the stable inorganic phosphazene core benefits the thermal stability of the polymers. Moreover, the number of benzoxazine moiety on phosphazene, which provide crosslinking sites also affected the thermal stability of polymers. Hence, the higher the benzoxazine ring contents, the better the thermal stability of the corresponding polybenzoxazines. After curing at the same condition, the gel fraction of six polymers is greater than $99 \%$, and it meant that a highly crosslinked polymer was obtained after the curing reaction.

It is also found that the char yields of cured benzoxazines deriving from $p-\mathrm{CF}_{3} \mathrm{PhOH}$ are a little higher than those of polybenzoxazines from $m-\mathrm{CF}_{3} \mathrm{PhOH}$. For example, the char yields of $\mathrm{P} 2 p$ are about $61.1 \%$ (in $\mathrm{N}_{2}$ ) and $51.0 \%$ (in air), respectively. Meanwhile, the char yields of $\mathrm{P} 2 m$ which has a similar structure to $\mathrm{P} 2 p$ are $48.9 \%$ (in $\mathrm{N}_{2}$ ) and $22.4 \%$ (in air), respectively. The difference was also found in other polybenzoxazines couples, such as among $\mathrm{P} 4 m$ and $\mathrm{P} 4 p$, $\mathrm{P} 3 m$ and $\mathrm{P} 3 p$. The possible explanation is that the steric hindrance of the $m-\mathrm{CF}_{3} \mathrm{PhOH}$ is higher than that 

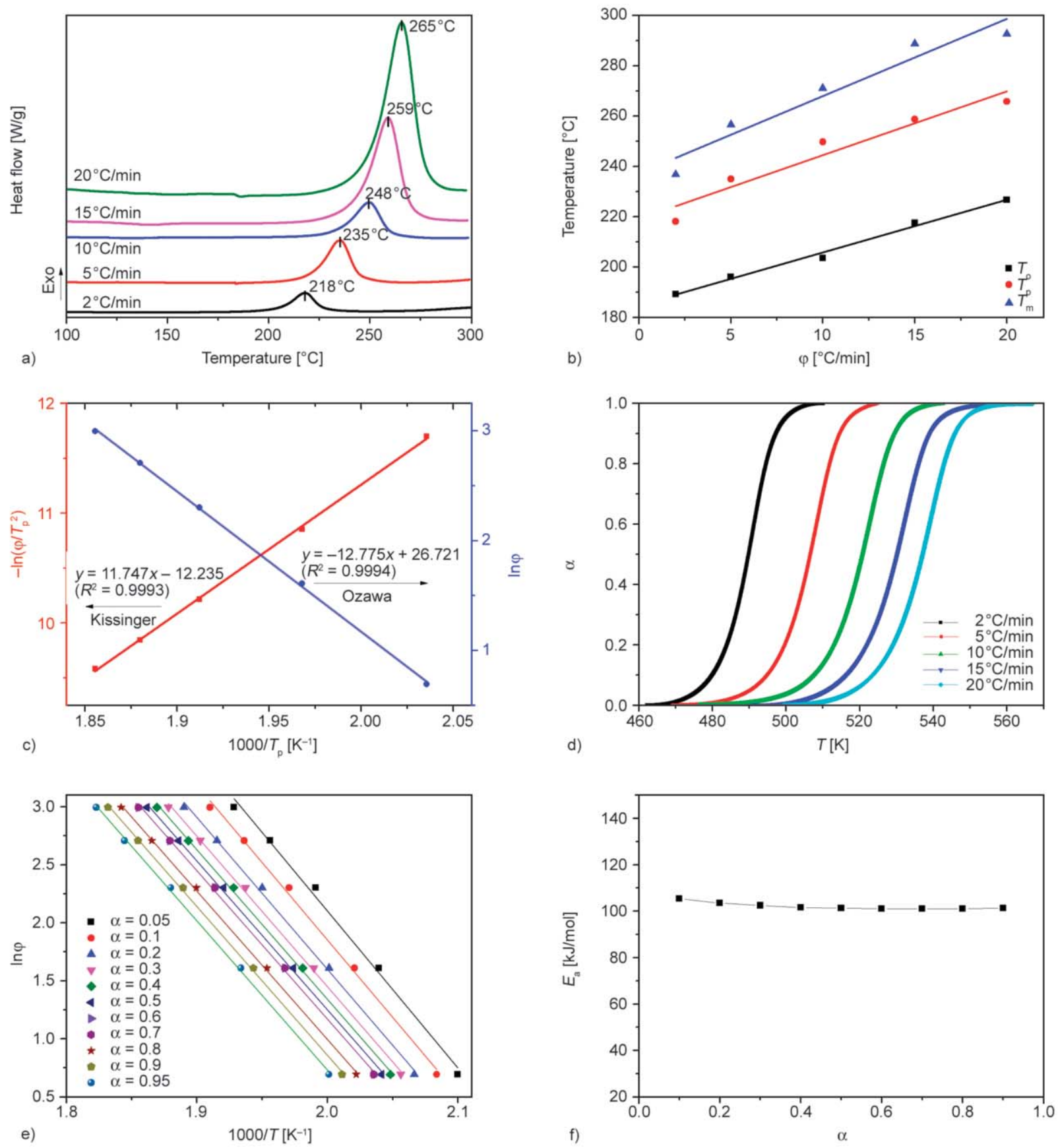

Figure 4. (a) The DSC curves of Monomer $3 m$ at different curing rates. (b) Relationship curves of curing parameters and heating rates. (c) Representation of Ozawa's and Kissinger's methods to calculate activation energy. (d) Conversion as a function of curing temperature. (e) $\ln \varphi \sim 1000 / T$ curves ( $\alpha=$ Degree of curing). (f) Representation FlynnWall-Ozawa's methods to calculate activation energy.

of the $p-\mathrm{CF}_{3} \mathrm{PhOH}$, consequently leads to lower crosslinking density (Table 3). As known, increasing the crosslinking density of thermosets is one of the most popular methods to improve the thermal stability of traditional polymers, such as in rubber curing.

\subsection{Dynamic mechanical analysis of the polybenzoxazines}

DMA is widely used to analyze the dynamic mechanical properties of polymers. Based on DMA results
(Figure 6), we can figure out $T_{\mathrm{g}}$, storage modulus, and crosslink density of the six polymers. The corresponding data were displayed in Table 3.

The co-substituent groups show notable effects on the properties of cured polymers according to data listed in Table 3 . Though all polybenzoxazines possess relatively high $T_{\mathrm{g}}$ (over $128^{\circ} \mathrm{C}$ ), the $T_{\mathrm{g}}$ values of polybenzoxazines deriving from $p-\mathrm{CF}_{3} \mathrm{PhOH}$ are little higher than that of polybenzoxazines from $m-\mathrm{CF}_{3} \mathrm{PhOH}$. The storage moduli and cross-linking 

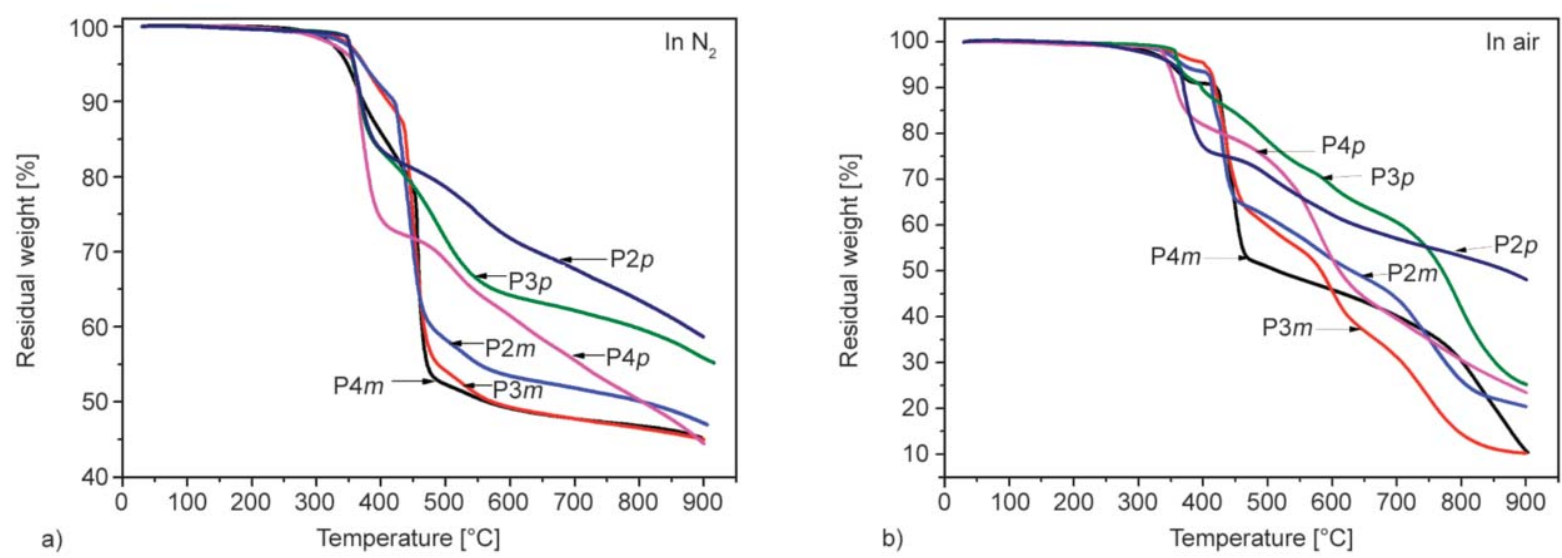

Figure 5. TGA curves of six polybenzoxazines. a) In $\mathrm{N}_{2}$, b) in air.

Table 3. Thermal and Mechanical properties of six polybenzoxazines.

\begin{tabular}{|c|c|c|c|c|c|c|c|c|c|c|c|}
\hline \multirow[t]{2}{*}{ Samples } & \multicolumn{2}{|c|}{$\begin{array}{l}{ }^{\mathrm{a}} \boldsymbol{T}_{\mathbf{5} \%} \\
{\left[{ }^{\circ} \mathbf{C}\right]}\end{array}$} & \multicolumn{2}{|c|}{$\begin{array}{c}{ }^{\mathrm{b}} \boldsymbol{T}_{10 \%} \\
\left.{ }^{\circ} \mathrm{C}\right] \\
\end{array}$} & \multicolumn{2}{|c|}{$\begin{array}{l}{ }^{\mathrm{c}} \boldsymbol{Y}_{\mathrm{c}} \\
{[\%]}\end{array}$} & \multirow{2}{*}{$\begin{array}{c}{ }^{\mathrm{d}} \boldsymbol{T}_{\mathrm{g}} \\
{\left[{ }^{\circ} \mathbf{C}\right]}\end{array}$} & \multirow{2}{*}{$\begin{array}{c}{ }^{\mathrm{e}} E^{\prime} \\
{[\mathbf{G P a}]}\end{array}$} & \multirow{2}{*}{$\begin{array}{c}\mathrm{f}\left(T_{\mathrm{g}}+40\right) \\
{[\mathrm{K}]}\end{array}$} & \multirow{2}{*}{$\begin{array}{c}{ }^{\mathrm{g}} E_{1}{ }^{\prime} \\
{[\mathrm{MPa}]}\end{array}$} & \multirow{2}{*}{$\begin{array}{c}{ }^{\mathrm{h}} \mathbf{v}_{\mathrm{e}} \\
{\left[\mathrm{mol} \cdot \mathrm{m}^{-3}\right]}\end{array}$} \\
\hline & $\mathbf{N}_{2}$ & air & $\mathbf{N}_{2}$ & air & $\mathbf{N}_{2}$ & air & & & & & \\
\hline $\mathrm{P} 4 m$ & 352 & 351 & 372 & 420 & 45.8 & 20.3 & 128 & 1.3 & 441 & 8.9 & 809 \\
\hline P3m & 373 & 403 & 411 & 418 & 46.2 & 10.9 & 147 & 0.7 & 460 & 9.4 & 818 \\
\hline $\mathrm{P} 2 m$ & 373 & 369 & 421 & 413 & 48.9 & 22.4 & 175 & 1.1 & 488 & 12.9 & 1058 \\
\hline $\mathrm{P} 4 p$ & 358 & 352 & 365 & 368 & 47.5 & 26.6 & 221 & 2.6 & 534 & 31.2 & 2342 \\
\hline $\mathrm{P} 3 p$ & 357 & 362 & 368 & 397 & 58.0 & 30.2 & 210 & 1.8 & 513 & 29.0 & 2265 \\
\hline $\mathrm{P} 2 p$ & 358 & 350 & 370 & 369 & 61.1 & 51.0 & 228 & 1.6 & 541 & 37.2 & 2757 \\
\hline
\end{tabular}

a $5 \%$ weight loss temperature;

${ }^{\mathrm{b}} 10 \%$ weight loss temperature;

cthe Char yields at $850^{\circ} \mathrm{C}$;

$\mathrm{d}_{\text {the glass transition temperature by DMA; }}$

ethe storage modulus at $50^{\circ} \mathrm{C}$;

fKelvin temperature of $\left(T_{\mathrm{g}}+40\right) \mathrm{K}$;

${ }^{\mathrm{g}}$ storage modulus at $\left(T_{\mathrm{g}}+40\right) \mathrm{K}$;

${ }^{h}$ the crosslinking density at $\left(T_{\mathrm{g}}+40\right) \mathrm{K}$ respectively from DMA values.

density show a similar trend as $T_{\mathrm{g}}$. Such result is attributed to the reason that $m-\mathrm{CF}_{3} \mathrm{PhOH}$ possesses greater steric hindrance than $p-\mathrm{CF}_{3} \mathrm{PhOH}$, hence the polybenzoxazines deriving from $m-\mathrm{CF}_{3} \mathrm{PhOH}$ have higher free volume at low temperature compared with the polymers deriving from $p-\mathrm{CF}_{3} \mathrm{PhOH}$. It means

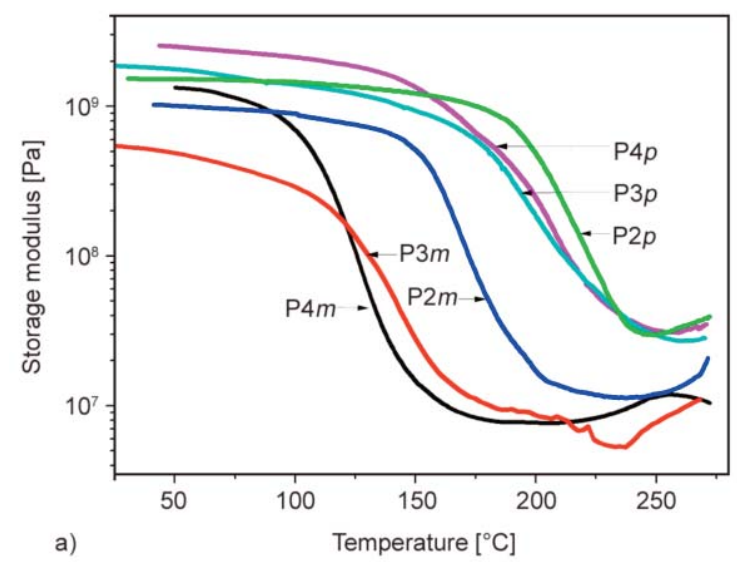

that segment movement of polymers deriving from $m-\mathrm{CF}_{3} \mathrm{PhOH}$ is easier than that of polymers from $p-\mathrm{CF}_{3} \mathrm{PhOH}$, so $m-\mathrm{CF}_{3} \mathrm{PhOH}$-containing polybenzoxazines show relatively lower $T_{\mathrm{g}}$. The storage moduli of the polymer depend on chemical structure and cross-linking density. Theses six polymers show

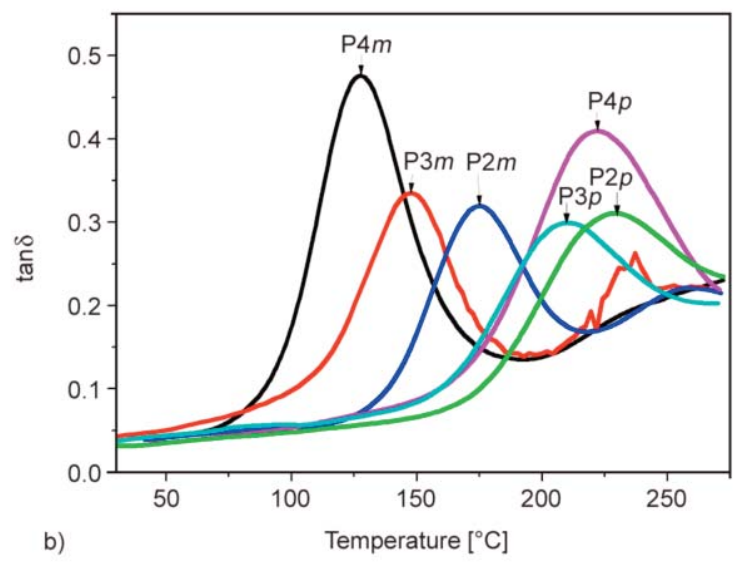

Figure 6. Storage moduli (a) and $\tan \delta$ (b) of the polybenzoxazines. 
similar chemical structure, and their storage modulus mainly depends on th crosslink density. As mentioned above, the larger steric hindrance of $m-\mathrm{CF}_{3} \mathrm{PhOH}$ prohibits the network formation during ring-opening polymerization and leads to a thermosetting resin with low crosslink density. The theoretic calculation of crosslinking density also gives solid support for this explanation. According to wellestablished rubber elasticity theory $[62,63]$, the crosslinking density $\left(v_{\mathrm{e}}\right)$ of a crosslinked network can be estimated using Equation (1):

$v_{e}=\frac{E_{1}{ }^{\prime}}{3 R T}$

where, $E_{1}{ }^{\prime}$ is the storage modulus at a temperature of $\left(T_{\mathrm{g}}+40\right)$ degree in the form of absolute temperature $[\mathrm{K}]$, so the $v_{\mathrm{e}}$ is less influenced by the hydrogen bonding. $R$ is the gas constant.

Although the equation was first put forward for lightly crosslinked materials, such as cured rubber, now it has been adopted widely to estimate the crosslink density of different polybenzoxazines. The crosslink densities of the six polybenzoxazines are shown in Table 3, it's very clear that crosslinkdensity of $p-\mathrm{CF}_{3} \mathrm{PhOH}$ series polybenzoxazines $(2342,2265$, $2757 \mathrm{~mol} \cdot \mathrm{m}^{-3}$ for $\mathrm{P} 4 p, \mathrm{P} 3 p, \mathrm{P} 2 p$, respectively) are much higher than that of the $m-\mathrm{CF}_{3} \mathrm{PhOH}$ series $(809$, $818,1058 \mathrm{~mol} \cdot \mathrm{m}^{-3}$ for $\mathrm{P} 4 m, \mathrm{P} 3 m, \mathrm{P} 2 m$, respectively), which supports the speculation that $m-\mathrm{CF}_{3} \mathrm{PhOH}$ series polymers have lower $T_{\mathrm{g}}$ compared with $p-\mathrm{CF}_{3} \mathrm{PhOH}$ series polybenzoxazines.

Here, we can conclude that carefully select the cosubstituent, we can obtain high-performance polybenzoxazines with different properties. For example, $m-\mathrm{CF}_{3} \mathrm{PhOH}$-derived polybenzoxazines show low $T_{\mathrm{g}}$, but we can imagine that this group of polymers will show high impact strength for its low crosslinking density; meanwhile, $p-\mathrm{CF}_{3} \mathrm{PhOH}$-derived polybenzoxazine showed excellent thermal properties for its high crosslinking density.

\subsection{Dielectric properties of monomers and cured polymers}

One of the potential application fields of polybenzoxazines is electronics packaging materials, hence evaluate the dielectric property of polybenzoxazines is necessary. The tests of dielectric properties of all six polybenzoxazines (Table 4) were carried out at room temperature in the frequency range of $100 \mathrm{~Hz}$ $1 \mathrm{MHz}$. Monomer $4 m$ and $3 m$ are viscous liquid therefore are not suitable for testing. All other monomers can be compressed into a tablet for the measurement. The dielectric constant of $2 m$ (having two $m$ - $\mathrm{CF}_{3} \mathrm{PhO}$ - groups) is $7.5,4 p, 3 p$ and $2 p$ which has four, three and two $p$ - $\mathrm{CF}_{3} \mathrm{PhO}$-groups, their dielectric constants are 7.1, 7.3, 7.4, respectively. Interestingly, all six samples show relatively high dielectric constant compared with that of previous reported fluorinated polybenzoxazines (2.42-2.19 [64], 2.3 [65]). From $\mathrm{P} 4 m$ to $\mathrm{P} 2 p$, the dielectric constants at $1 \mathrm{MHz}$ are 5.0, 5.6, 5.7, 5.3, 5.8 and 5.9, respectively. The dielectric constant of materials depends directly on its polarizability, increasing the polarizability benefits to improve dielectric constants. Obviously, polymer's dielectric properties rely strongly on its chemical structure. Therefore, the high dielectric constant of six polymers is possibly due to orientational polarization of two kinds of polar groups present in cured polymers: polar co-substituents $\left(\mathrm{m} / \mathrm{p}-\mathrm{CF}_{3} \mathrm{PhOH}\right)$ and the end-capped phenol groups resulting from ring-opening of benzoxazines. $\mathrm{CF}_{3}-$ is a strong electron-withdrawing group, both $m-\mathrm{CF}_{3} \mathrm{PhOH}$ and $p-\mathrm{CF}_{3} \mathrm{PhOH}$ possess high polarity whether the $\mathrm{CF}_{3}$-group locates on meta- or para-position. For monomer $4 m$ and $4 p$, which have higher $m-\mathrm{CF}_{3} \mathrm{PhOH} / p-\mathrm{CF}_{3} \mathrm{PhOH}$ content, they play dominated role in corresponding high dielectric constant polybenzoxazines. For monomer $2 m$ and $2 p$, which possess higher $\mathrm{BOZ}$ content, the high dielectric constant of corresponding polymers depends mainly on polar phenol group attached to the network (Figure 7). These two benzoxazine monomers possess molecular weight as high as $1362.1 \mathrm{~g} / \mathrm{mol}$, which will lead to high viscosity mixtures at the initial stage of polymerization and then hinder the formation of uniform cross-linking network. Some polar phenol groups appear at the chain end and take place orientational polarization under an applied voltage. Certainly, the co-substituent also contributed to the dielectric constant of $\mathrm{P} 2 m$ and $\mathrm{P} 2 p$.

In addition to the dielectric constant, dielectric loss is another key factor for dielectric materials, and low dielectric loss is beneficial for electronic applications. From Table 4 we can find out that all six polybenzoxazines show a low dielectric loss at $1 \mathrm{MHz}$ $(0.016,0.0089,0.0084,0.014,0.0097$, and 0.0067, respectively). Among them, the dielectric loss of $\mathrm{P} 4 m$ and $\mathrm{P} 4 p$ are a little higher than that of the other four polymers, which is attributed to lower crosslinking density of $\mathrm{P} 4 m$ and $\mathrm{P} 4 p$. The dielectric loss of 

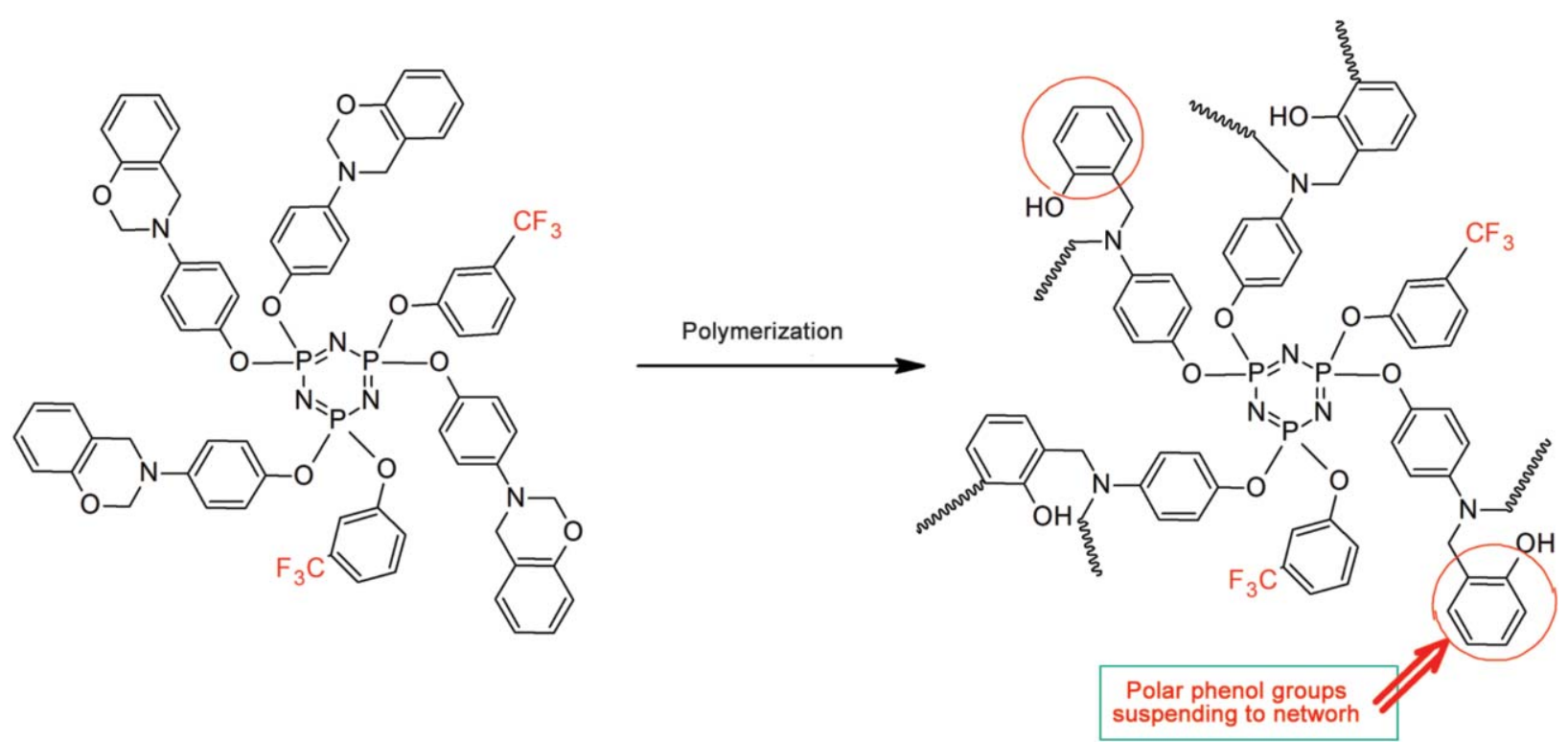

Figure 7. The polar end-phenol group formation during thermal polymerization.

Table 4. Dielectric property of monomers and polymers.

\begin{tabular}{l|c|c|c|c|c|c|c|c|c|c|c|c|}
\hline \multicolumn{1}{|c|}{ Samples } & $\mathbf{4 m}$ & $\mathbf{3 m}$ & $\mathbf{2 m}$ & $\mathbf{4} \boldsymbol{p}$ & $\mathbf{3} \boldsymbol{p}$ & $\mathbf{2} \boldsymbol{p}$ & $\mathbf{P 4} \boldsymbol{m}$ & $\mathbf{P 3} \boldsymbol{m}$ & $\mathbf{P 2} \boldsymbol{m}$ & $\mathbf{P 4} \boldsymbol{p}$ & $\mathbf{P 3} \boldsymbol{p}$ & $\mathbf{P 2} \boldsymbol{p}$ \\
\hline$\varepsilon(1 \mathrm{MHz})$ & - & - & 7.5 & 7.1 & 7.3 & 7.4 & 5.0 & 5.6 & 5.7 & 5.3 & 5.8 & 5.9 \\
\hline $\tan \delta(1 \mathrm{MHz})$ & - & - & 0.020 & 0.028 & 0.024 & 0.023 & 0.016 & 0.0089 & 0.0084 & 0.014 & 0.0097 & 0.0067 \\
\hline
\end{tabular}

monomers is higher than their corresponding polymers.

\subsection{The surface properties and water absorption of polybenzoxazines}

The properties of thermosets are affected by moisture in the air during storage and in service, such as electric properties. So, the water absorption/penetration ability of the polymer is very crucial to its practical utilization as electric materials. In recent years, the polybenzoxazines have been regarded as a new kind of low surface energy materials for its high hydrophobic nature and low water absorption character. The surface wettability characteristics of the six samples were investigated by water contact angle (WCA) measurement [66]. The advancing contact angle $\left(\theta_{\mathrm{a}}\right)$, receding contact angle $\left(\theta_{\mathrm{r}}\right)$ and surface free energy of six novel polybenzoxazines were displayed in Table 5. $\theta_{\mathrm{r}}$ is more sensitive to the surface condition than $\theta_{\mathrm{a}}$, therefore the $\theta_{\mathrm{a}}$-related data are suitable for calculating the surface free energy. Compared with reported results $[67,68]$, the six new polymers don't show high hydrophobic properties, and all $\theta_{\text {a }}$ values of six polymers are not more than $90^{\circ}$. Wang et al. [67] attributed these results to the perfect hydrogen-binding network which resulting in high hydrophobicity in polybenzoxazines was disrupted by higher curing temperatures, and concluded that the ratio of intra- and intermolecular hydrogen bonds affected the surface property seriously. From the FTIR spectra of six polybenzoxazines (Figure 8), we can find out three different kinds of hydrogen bonds:

Table 5. The surface properties of six polybenzoxazines.

\begin{tabular}{|c|c|c|c|c|c|c|c|}
\hline \multirow[t]{2}{*}{ Sample } & \multicolumn{2}{|c|}{$\begin{array}{c}\theta_{\mathrm{a}} \\
{\left[^{\circ}\right]}\end{array}$} & \multirow{2}{*}{$\begin{array}{c}\gamma \\
{\left[\mathrm{mJ} / \mathrm{m}^{2}\right]}\end{array}$} & \multicolumn{2}{|c|}{ Water } & \multicolumn{2}{|c|}{$\begin{array}{c}\text { Water absorption (13 d) } \\
{[\%]}\end{array}$} \\
\hline & Water & Hexadecane & & $\begin{array}{l}\theta_{\mathbf{r}} \\
{\left[^{\circ}\right]}\end{array}$ & $\begin{array}{c}\text { CAH } \\
{\left[{ }^{\circ}\right]}\end{array}$ & $R H=33 \%$ & $R H=75 \%$ \\
\hline $\mathrm{P} 4 m$ & $85 \pm 0.5$ & $25 \pm 1.0$ & 30.2 & $65 \pm 2.0$ & 20 & 0.65 & 0.67 \\
\hline $\mathrm{P} 3 m$ & $78 \pm 1.0$ & $23 \pm 1.5$ & 32.3 & $56 \pm 3.0$ & 22 & 0.82 & 0.79 \\
\hline $\mathrm{P} 2 m$ & $76 \pm 1.5$ & $24 \pm 1.5$ & 34.5 & $52 \pm 2.5$ & 20 & 0.85 & 0.86 \\
\hline $\mathrm{P} 4 p$ & $90 \pm 0.5$ & $28 \pm 2.0$ & 27.9 & $68 \pm 2.0$ & 22 & 0.19 & 0.21 \\
\hline $\mathrm{P} 3 p$ & $88 \pm 1.0$ & $31 \pm 1.5$ & 28.2 & $60 \pm 1.5$ & 28 & 0.23 & 0.29 \\
\hline $\mathrm{P} 2 p$ & $81 \pm 1.5$ & $27 \pm 2.5$ & 31.7 & $57 \pm 2.5$ & 24 & 0.38 & 0.41 \\
\hline
\end{tabular}




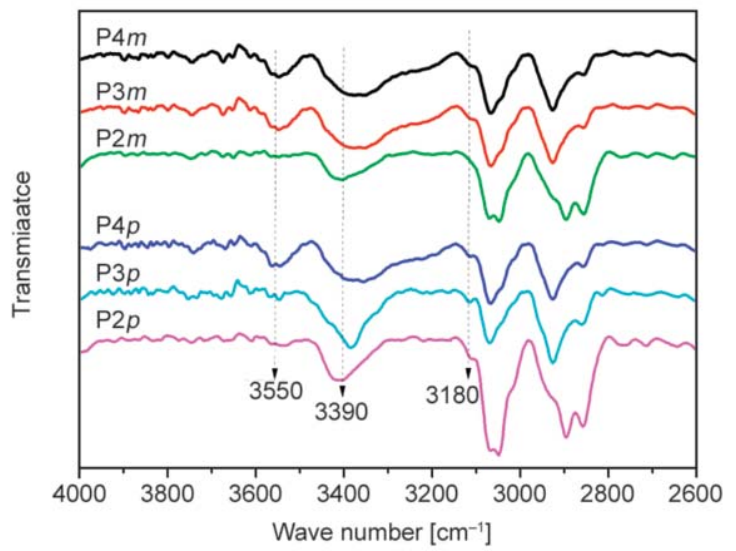

Figure 8. FTIR spectra of six polybenzoxazines.

$3550 \mathrm{~cm}^{-1}$ indicating $-\mathrm{OH} . . . \pi$ intramolecular hydrogen bonds, $3400-3370 \mathrm{~cm}^{-1}$ indicating $-\mathrm{OH}$... $\mathrm{O}$ intermolecular hydrogen bonds, $3180 \mathrm{~cm}^{-1}$ indicating $-\mathrm{OH}$... $\mathrm{N}$ intramolecular hydrogen bonds. These results are consistent very well with reported data; the surface free energies of the six polymers are higher than $27 \mathrm{~mJ} / \mathrm{m}^{2}$.

Before water absorption test, all samples were dried under vacuum at $90^{\circ} \mathrm{C}$ for $24 \mathrm{~h}$ to constant weight and placed in a testing box (33\% and $75 \% \mathrm{RH}$, at room temperature) for different times. The water absorption content of the samples was listed in Table 5. Though the six polybenzoxazines are somewhat hydrophilic, all samples show relatively low humidity absorption ability whether the relative humidity is low (33\%) or high $(75 \%)$, which makes the branched polybenzoxazines suitable for some special applications, such as underfilling in the electronic packaging encapsulation. Analyzing these results, we can find out that the water absorption ability of $m-\mathrm{CF}_{3} \mathrm{PhOH}$ derived polybenzoxazines is bigger than that of $p-\mathrm{CF}_{3} \mathrm{PhOH}$-derived polybenzoxazines. The result is consistent very with above-mentioned facts, that is, $m-\mathrm{CF}_{3} \mathrm{PhOH}$-containing polybenzoxazines has lower crosslinking density compared with $p-\mathrm{CF}_{3} \mathrm{PhOH}$-containing ones.

\section{Conclusions}

In this paper, we provide a novel route to prepare branched benzoxzine resins with low melting point and still hold excellent thermal and mechanic properties. Though the molecular weight of six benzoxazine monomers is larger than $1230 \mathrm{~g} / \mathrm{mol}$, two of them appear as a liquid at $25^{\circ} \mathrm{C}$ and the melting point of the other four monomers is below $60^{\circ} \mathrm{C}$. All six monomers also possess high solubility in common organic solvent; these merits make them easily processable both in melt and in solution. Polybenzoxazines derived from $p-\mathrm{CF}_{3} \mathrm{PhOH}$ exhibit higher $T_{\mathrm{g}}$ and thermal stability than $m-\mathrm{CF}_{3} \mathrm{PhOH}$-derived polybenzoxazines. Unlike the traditional bisphenolA derived polybenzoxazines which normally shows a low dielectric constant and low dielectric loss, the newly developed cyclotriphosphazene-based polymers show relatively high dielectric constant but still remain low dielectric loss. Though all polybenzoxazines contain $\mathrm{CF}_{3}$ group, they don't show high hydrophobic properties.

\section{Acknowledgement}

This work was supported by the National Natural Science Foundation of China (No. 21274049).

\section{References}

[1] Kiskan B.: Adapting benzoxazine chemistry for unconventional applications. Reactive and Functional Polymers, 129, 76-88 (2018).

https://doi.org/10.1016/j.reactfunctpolym.2017.06.009

[2] Kim H-J., Brunovska Z., Ishida H.: Synthesis and thermal characterization of polybenzoxazines based on acetylene-functional monomers. Polymer, 40, 65656573 (1999).

https://doi.org/10.1016/S0032-3861(99)00046-4

[3] Zhang K., Liu J., Ishida H.: High performance crosslinked polyimide based on main-chain type polybenzoxazine. RSC Advances, 4, 62550-62556 (2014). https://doi.org/10.1039/C4RA12015A

[4] Chernykh A., Agag T., Ishida H.: Synthesis of linear polymers containing benzoxazine moieties in the main chain with high molecular design versatility via click reaction. Polymer, 50, 382-390 (2009). https://doi.org/10.1016/j.polymer.2008.11.017

[5] Wan L., Wang J., Sun Y., Feng C., Li K.: Polybenzoxazine-based nitrogen-containing porous carbons for high-performance supercapacitor electrodes and carbon dioxide capture. RSC Advances, 5, 5331-5342 (2015). https://doi.org/10.1039/C4RA13637C

[6] Thirukumaran P., Shakila A., Muthusamy S.: Synthesis and characterization of novel bio-based benzoxazines from eugenol. RSC Advances, 4, 7959-966 (2014). https://doi.org/10.1039/C3RA46582A

[7] Yen Y-C., Cheng C-C., Chu Y-L., Chang F-C.: A new benzoxazine containing uracil, complementary functionality. Polymer Chemistry, 2, 1648-1653 (2011). https://doi.org/10.1039/c1py00093d

[8] Liu J., Ishida H.: Anomalous isomeric effect on the properties of bisphenol F-based benzoxazines: Toward the molecular design for higher performance. Macromolecules, 47, 5682-5690 (2014). https://doi.org/10.1021/ma501294y 
[9] Arslan M., Kiskan B., Yagci Y.: Combining elemental sulfur with polybenzoxazines via inverse vulcanization. Macromolecules, 49, 767-773 (2016).

https://doi.org/10.1021/acs.macromol.5b02791

[10] Ishida H., Ohba S.: Synthesis and characterization of maleimide and norbornene functionalized benzoxazines. Polymer, 46, 5588-5595 (2005).

https://doi.org/10.1016/j.polymer.2005.04.080

[11] Zou X., Yang X., Xu M., Jia K., Liu X.: Curing behaviors and properties of allyl- and benzoxazine-functional phthalonitrile with improved processability. Journal of Polymer Research, 23, 2-11 (2016).

https://doi.org/10.1007/s10965-015-0891-3

[12] Baqar M., Agag T., Ishida H., Qutubuddin S.: Polymerization behavior of methylol-functional benzoxazine monomer. Reactive and Functional Polymers, 73, 360 368 (2013).

https://doi.org/10.1016/j.reactfunctpolym.2012.04.017

[13] Zhang K., Han M., Liu Y., Froimowicz P.: Design and synthesis of bio-based high-performance trioxazine benzoxazine resin via natural renewable resources. ACS Sustainable Chemistry and Engineering, 7, 93999407 (2019).

https://doi.org/10.1021/acssuschemeng.9b00603

[14] Zhang K., Han M., Han L., Ishida H.: Resveratrolbased tri-functional benzoxazines: Synthesis, characterization, polymerization, and thermal and flame retardant properties. European Polymer Journal, 116, 526533 (2019).

https://doi.org/10.1016/j.eurpolymj.2019.04.036

[15] Chen C. H., Yu T. Y., Wu J-H., Ariraman M., Juang T-Y., Abu-Omar M-M., Lin C-H.: Synthesis and properties of quinoxaline-containing benzoxazines and polybenzoxazines. ACS Omega, 4, 9092-9101 (2019). https://doi.org/10.1021/acsomega.9b01042

[16] Zhang L., Zhao Z., Dai Z., Xu L., Fu F., Endo T., Liu X.: Unexpected healability of an ortho-blocked polybenzoxazine resin. ACS Macro Letters, 8, 506-511 (2019). https://doi.org/10.1021/acsmacrolett.9b00083

[17] Chen W-C., Kuo S-W.: Ortho-imide and allyl groups effect on highly thermally stable polybenzoxazine/double-decker-shaped polyhedral silsesquioxane hybrids. Macromolecules, 51, 9602-9612 (2018). https://doi.org/10.1021/acs.macromol.8b02207

[18] Zhang S., Ran Q., Fu Q., Gu Y.: Preparation of transparent and flexible shape memory polybenzoxazine film through chemical structure manipulation and hydrogen bonding control. Macromolecules, 51, 65616570 (2018).

https://doi.org/10.1021/acs.macromol.8b01671

[19] He Y., Gao S., Lu Z.: A mussel-inspired polybenzoxazine containing catechol groups. Polymer, 158, 53-58 (2018).

https://doi.org/10.1016/j.polymer.2018.10.046
[20] Salum M-L., Iguchi D., Arza C-R., Han L., Ishida H., Froimowicz P.: Making benzoxazines greener: Design, synthesis, and polymerization of a biobased benzoxazine fulfilling two principles of green chemistry. ACS Sustainable Chemistry and Engineering, 6, 1309613106 (2018).

https://doi.org/10.1021/acssuschemeng.8b02641

[21] Chen Y-P., He X-Y., Dayo A. Q., Wang J-Y., Liu W-B., Wang J., Tao T.: Synthesis and characterization of cardanol containing tetra-functional fluorene-based benzoxazine resin having two different oxazine ring structures. Polymer, 179, 121620/1-121620/7 (2019).

https://doi.org/10.1016/j.polymer.2019.121620

[22] Wan L., Han D., Liu Q., Xu Z., Huang F.: Polyetherbased main-chain-type polytriazole elastomer with benzoxazine via a 1,3-dipolar cycloaddition reaction. Journal of Applied Polymer Science, 133, 42821-42828 (2016).

https://doi.org/10.1002/app.42820

[23] Zhang K., Zhuang Q., Liu X., Yang G., Cai R., Han Z.: A new benzoxazine containing benzoxazole-functionalized polyhedral oligomeric silsesquioxane and the corresponding polybenzoxazine nanocomposites. Macromolecules, 46, 2696-2704 (2013).

https://doi.org/10.1021/ma400243t

[24] Qu L., Xin Z.: Preparation and surface properties of novel low surface free energy fluorinated silane-functional polybenzoxazine films. Langmuir, 27, 83658370 (2011).

https://doi.org/10.1021/la200073v

[25] Yang L., Raza A., Si Y., Mao X., Shang Y., Ding B., Yu J., Al-Deyab S. S.: Synthesis of superhydrophobic silica nanofibrous membranes with robust thermal stability and flexibility via in situ polymerization. Nanoscale, $\mathbf{4}$, 6581-6587 (2012).

https://doi.org/10.1039/c2nr32095a

[26] Liao C-S., Wang C-F., Lin H-C., Chou H-Y., Chang F-C.: Fabrication of patterned superhydrophobic polybenzoxazine hybrid surfaces. Langmuir, 25, 3359-3362 (2009). https://doi.org/10.1021/la900176c

[27] Wang C-F., Chiou S-F., Ko F-H., Chen J-K., Chou C-T., Huang C-F., Kuo S-W., Chang F-C.: Polybenzoxazine as a mold-release agent for nanoimprint lithography. Langmuir, 23, 5868-5871 (2007). https://doi.org/10.1021/la062921e

[28] Raza A., Si Y., Ding B., Yu J., Sun G.: Fabrication of superhydrophobic films with robust adhesion and dual pinning state via in situ polymerization. Journal of Colloid and Interface Science, 395, 256-262 (2013). https://doi.org/10.1016/j.jcis.2012.11.030

[29] Wang H., Wang J., He X., Feng T., Ramdani N., Luan M., Liu W., Xu X.: Synthesis of novel furan-containing tetrafunctional fluorene-based benzoxazine monomer and its high performance thermoset. RSC Advances, 4, 64798-64801 (2014). https://doi.org/10.1039/C4RA10946E 
[30] Zhang S., Yin S., Ran Q., Fu Q., Gu Y.: Facile preparation of polybenzoxazine/graphene nanocomposites for electromagnetic interference shielding. Polymer, 162, 20-28 (2019).

https://doi.org/10.1016/j.polymer.2018.12.024

[31] Li Y., Liu X., Nie X., Yang W., Wang Y., Yu R., Shui J.: Multifunctional organic-inorganic hybrid aerogel for self-cleaning, heat-insulating, and highly efficient microwave absorbing material. Advanced Functional Materials, 29, 1807624/1-1807624/9 (2019).

https://doi.org/10.1002/adfm.201807624

[32] Li J., Shen Z., Li H., Xu L., Song H., Guan G., Liu G.: Reinforced properties of polybenzoxazine-based nanocomposites with siloxane benzoxazine-modified halloysite nanotubes. Journal of Applied Polymer Science, 136, 47882/1-47882/9 (2019).

https://doi.org/10.1002/app.47882

[33] Zhao Z., Lou Y., Dai Z., Fu F., Liu X.: Biobased composites prepared using an environmentally friendly water-slurry methodology. Industrial and Engineering Chemistry Research, 57, 7881-7888 (2018).

https://doi.org/10.1021/acs.iecr.8b00960

[34] Brown E. A., Rider D. A.: Pegylated polybenzoxazine networks with increased thermal stability from miscible blends of tosylated poly(ethylene glycol) and a benzoxazine monomer. Macromolecules, 50, 6468-6481 (2017). https://doi.org/10.1021/acs.macromol.7b01457

[35] Dayo A. Q., Wang A-R., Kiran S., Wang J., Qureshi K., Xu Y-L., Zegaoui A., Babar A. A., Liu W-B.: Impacts of hemp fiber diameter on mechanical and water uptake properties of polybenzoxazine composites. Industrial Crops and Products, 111, 277-284 (2018).

https://doi.org/10.1016/j.indcrop.2017.10.039

[36] Monisha M., Amarnath N., Mukherjee S., Lochab B.: Cardanol benzoxazines: A versatile monomer with advancing applications. Macromolecular Chemistry and Physics, 220, 1800470/1-1800470/14 (2019).

https://doi.org/10.1002/macp.201800470

[37] Sharma P., Kumar D., Roy K.: Enhancing the processibility of high temperature polymerizing cardanol derived benzoxazines using eco-friendly curing accelerators. Polymer, 138, 343-351 (2018).

https://doi.org/10.1016/j.polymer.2018.01.084

[38] Selvaraj V., Jayanthi K-P., Alagar M.: Livestock chicken feather fiber reinforced cardanol benzoxazine-epoxy composites for low dielectric and microbial corrosion resistant applications. Polymer Composites, in press (2019).

https://doi.org/10.1002/pc.25275

[39] Lou Y., Zhao Z., Chen Z., Dai Z., Fu F., Zhang Y., Zhang Z., Liu X.: Processability improvement of a 4-vinlyguiacol derived benzoxazine using reactive diluents. Polymer, 160, 316-324 (2019).

https://doi.org/10.1016/j.polymer.2018.11.056
[40] Kobzar Y. L., Tkachenko I. M., Bliznyuk V. N., Shevchenko V. V.: Fluorinated polybenzoxazines as advanced phenolic resins for leading-edge applications. Reactive and Functional Polymers, 133, 71-92 (2018). https://doi.org/10.1016/j.reactfunctpolym.2018.10.004

[41] Kobzar Y. L., Tkachenko I. M., Bliznyuk V. N., Lobko E. V., Shekera O. V., Shevchenko V. V.: Synthesis and characterization of fluorinated isomeric polybenzoxazines from core-fluorinated diamine-based benzoxazines. Polymer, 145, 62-69 (2018). https://doi.org/10.1016/j.polymer.2018.04.070

[42] Gao Y., Huang F., Yuan Q., Zhou Y., Du L.: Synthesis of novel imide-functionalized fluorinated benzoxazines and properties of their thermosets. High Performance Polymers, 25, 677-684 (2013). https://doi.org/10.1177/0954008313480372

[43] Hamerton I., Howlin B. J., Mitchell A. L., McNamara L. T., Takeda S.: Systematic examination of thermal, mechanical and dielectrical properties of aromatic polybenzoxazines. Reactive and Functional Polymers, 72, 736-744 (2012).

https://doi.org/10.1016/j.reactfunctpolym.2012.07.001

[44] Parveen A-S., Thirukumaran P., Sarojadevi M.: Low dielectric materials from fluorinated polybenzoxazines. Polymers for Advanced Technologies, 25, 1538-1545 (2014). https://doi.org/10.1002/pat.3398

[45] Lin C. H., Chang S. L., Lee H. H., Chang H. C., Hwang K. Y., Tu A. P., Su W. C.: Fluorinated benzoxazines and the structure-property relationship of resulting polybenzoxazines. Journal of Polymer Science Part A: Polymer Chemistry, 46, 4970-4983 (2008).

https://doi.org/10.1002/pola.22823

[46] Demir K. D., Kiskan B., Latthe S. S., Demirel A. L., Yagci Y.: Thermally curable fluorinated main chain benzoxazine polyethers via Ullmann coupling. Polymer Chemistry, 4, 2106-2114 (2013). https://doi.org/10.1039/c2py21029k

[47] Velez-Herrera P., Doyama K., Abe H., Ishida H.: Synthesis and characterization of highly fluorinated polymer with the benzoxazine moiety in the main chain. Macromolecules, 41, 9704-9714 (2008).

https://doi.org/10.1021/ma801253a

[48] Shang Y., Si Y., Raza A., Yang L., Mao X., Ding B., Yu J.: An in situ polymerization approach for the synthesis of superhydrophobic and superoleophilic nanofibrous membranes for oil-water separation. Nanoscale, 4, 7847-7854 (2012).

https://doi.org/10.1039/C2NR33063F

[49] Tang X., Si Y., Ge J., Ding B., Liu L., Zheng G., Luo W., Yu J.: In situ polymerized superhydrophobic and superoleophilic nanofibrous membranes for gravity driven oil-water separation. Nanoscale, 5, 11657-11664 (2013). https://doi.org/10.1039/C3NR03937D 
[50] Ma W., Zhang Q., Samal S. K., Wang F., Gao B., Pan H., Xu H., Yao J., Zhan X., De Smedt S. C., Huang C.: Core-sheath structured electrospun nanofibrous membranes for oil-water separation. RSC Advances, 6, 41861-41870 (2016).

https://doi.org/10.1039/C6RA06224E

[51] Su Y-C., Chang F-C.: Synthesis and characterization of fluorinated polybenzoxazine material with low dielectric constant. Polymer, 44, 7989-7996 (2003). https://doi.org/10.1016/j.polymer.2003.10.026

[52] Raza A., Si Y., Wang X., Ren T., Ding B., Yu J., AlDeyab S.: Novel fluorinated polybenzoxazine-silica films: Chemical synthesis and superhydrophobicity. RSC Advances, 2, 12804-12811 (2012). https://doi.org/10.1039/C2RA21138F

[53] Velez-Herrera P., Ishida H.: Synthesis and characterization of highly fluorinated diamines and benzoxazines derived therefrom. Journal of Fluorine Chemistry, 130, 573-580 (2009). https://doi.org/10.1016/j.jfluchem.2009.04.002

[54] Tan Z-W., Wu X., Zhang M., Qiu J-J., Liu C-M.: Synthesis and properties of main-chain oligomeric benzoxazine precursor containing cyclotriphosphazene units. High Performance Polymers, 26, 906-913 (2014). https://doi.org/10.1177/0954008314533980

[55] Wu X., Zhou Y., Liu S-Z., Guo Y-N., Qiu J-J., Liu C-M.: Highly branched benzoxazine monomer based on cyclotriphosphazene: Synthesis and properties of the monomer and polybenzoxazines. Polymer, 52, 1004-1012 (2011).

https://doi.org/10.1016/j.polymer.2011.01.003

[56] Wu X., Liu S-Z., Tian D-T., Qiu J-J., Liu C-M.: Welldefined organic-inorganic hybrid benzoxazine monomers based on cyclotriphosphazene: Synthesis, properties of the monomers and polybenzoxazines. Polymer, 52, 4235-4245 (2011). https://doi.org/10.1016/j.polymer.2011.07.037

[57] Ma H-X., Zhao C., Qiu J-J., Liu Y., Liu C-M.: Synthesis of branched benzoxazine monomers with high molecular mass, wide processing window, and properties of corresponding polybenzoxazines. Journal of Applied Polymer Science, 134, 44453/1-44453/10 (2017). https://doi.org/10.1002/app.44453

[58] Jubsilp C., Damrongsakkul S., Takeichi T., Rimdusit S.: Curing kinetics of arylamine-based polyfunctional benzoxazine resins by dynamic differential scanning calorimetry. Thermochimica Acta, 447, 131-140 (2006). https://doi.org/10.1016/j.tca.2006.05.008
[59] Wang M. W., Jeng R. J., Lin C. H.: Study on the ringopening polymerization of benzoxazine through multisubstituted polybenzoxazine precursors. Macromolecules, 48, 530-535 (2015). https://doi.org/10.1021/ma502336j

[60] Liu Y., Hao Z., Lv S., Huang J., Liao C., Run M.: Structural effects of diamines on synthesis, polymerization, and properties of benzoxazines based on o-allylphenol. Polymer, 57, 29-38 (2015). https://doi.org/10.1016/j.polymer.2014.12.005

[61] Liu Y-L., Wu C-S., Chiu Y-S., Ho W-H.: Preparation, thermal properties, and flame retardance of epoxy-silica hybrid resins. Journal of Polymer Science Part A: Polymer Chemistry, 41, 2354-2367 (2003). https://doi.org/10.1002/pola.10778

[62] Guo G., Sun J., Zhao C., Liu Y., Liu C-M.: Phosphorus-containing polymers from THPS. VII. Synthesis of phosphorus-containing trialkynes and their metal-free 1,3-dipolar cycloaddition reaction with azidated soybean-oil. Green Chemistry, 18, 1278-1286 (2016). https://doi.org/10.1039/C5GC01919B

[63] Ambrožič R., Šebenik U., Krajnž M.: Epoxy emulsions stabilized with reactive bio-benzoxazine surfactant from epoxidized cardanol for coatings. European Polymer Journal, 81, 138-151 (2016). https://doi.org/10.1016/j.eurpolymj.2016.05.029

[64] Zhang K., Han L., Froimowicz P., Ishida H.: A smart latent catalyst containing $o$-trifluoroacetamide functional benzoxazine: Precursor for low temperature formation of very high performance polybenzoxazole with low dielectric constant and high thermal stability. Macromolecules, 50, 6552-6560 (2017). https://doi.org/10.1021/acs.macromol.7b00887

[65] Kobzar Y. L., Tkachenko I. M., Lobko E. V., Shekera O. V., Syrovets A. P., Shevchenko V. V.: Low dielectric material from novel core-fluorinated polybenzoxazine. Mendeleev Communications, 27, 41-43 (2017). https://doi.org/10.1016/j.mencom.2017.01.012

[66] Bai J., Shi Z., Yin J.: A novel main chain benzoxazine polymer with the ability of UV-induced self-surface modification. Polymer, 54, 2498-2505 (2013). https://doi.org/10.1016/j.polymer.2013.03.031

[67] Wang C-F., Su Y-C., Kuo S-W., Huang C-F., Sheen Y-C., Chang F-C.: Low-surface-free-energy materials based on polybenzoxazines. Angewandte Chemie International Edition, 45, 2248-2251 (2006). https://doi.org/10.1002/anie.200503957

[68] Zhou C., Lin J., Lu X., Xin Z.: Enhanced corrosion resistance of polybenzoxazine coatings by epoxy incorporation. RSC Advances, 6, 28428-28434 (2016). https://doi.org/10.1039/C6RA02215D 